University of Rhode Island

DigitalCommons@URI

Open Access Master's Theses

1971

\title{
La Tentation de la Saintete Chez Albert Camus
}

Aouicha Elosmani Hilliard

University of Rhode Island

Follow this and additional works at: https://digitalcommons.uri.edu/theses

\section{Recommended Citation}

Hilliard, Aouicha Elosmani, "La Tentation de la Saintete Chez Albert Camus" (1971). Open Access Master's Theses. Paper 1533.

https://digitalcommons.uri.edu/theses/1533

This Thesis is brought to you for free and open access by DigitalCommons@URI. It has been accepted for inclusion in Open Access Master's Theses by an authorized administrator of DigitalCommons@URI. For more information, please contact digitalcommons-group@uri.edu. 


\section{IA TENTATION DE IA SAINTETE \\ CHEZ ALBERT CAMUUS}

BY

AOUICHA ELOSMANI HILLIARD

A THESIS SUBMITTED IN PARTIAI FULFILLNENT OF THE REQUIREMENTS FOR THE DEGREE OF

MASTER OF ARTS

IN

FRENCH

UNIVERSITY OF RHODE ISLAND

1971 


\section{ABSTRACT}

Throughout his literary career Albert Camus reveals in his works a preoccupation with morality, a concern so intense that he seems to be directing himself on a quest for sainthood. The purpose of this thesis is to consider Camus' quest as it is revealed in inis woriss and to demonstrate its affinities with the quest of the Christian saint.

The iciea of the absurd is the basis of Camus' philosophy or life; it constitutes the only difference betweer his conception of sainthood and that of the Christian faith. The Christian saint follows the precepts of Christ because he believes in God; many of Camus' heroes, although they affirm that the heavens are silent, conduct themselves according to a rigorous morality based on the same religious precepts.

This essay demonstrates how Camus' concern with rorality-- his quest for sainthood-- influences his treatment of the major themes in his works; it traces the increasingly religious tendency of his thought. 
Through his treatment of the theme of death, Camus defines his philosophical position. Though death may sometimes seem a means of attaining the absolute, a universe where truth alone holds sway, Camus rejects it vehemently.

Instead, he espouses the idea of revolt-- a revolt against death, against the injustice of creation, and against the existence of evil. Moreover, he rejects those who choose violent and therefore self-dereating means in struggling against evil. The courage to protest, the purity of both ends and means, these are the virtues of the Christian saint.

The theme of revolt marks Camus' evolution-beginning with La Peste-- toward a deeper interest in the lot of his fellow men. In this second phase appear also the themes of solidarity and of justice. The characters in La Peste, Ies Justes and certain short stories in I'Exil et le Royaume illustrate this new moral dimension in his writings; like Christ, they are ready to dedicate their lives to redeeming those or others.

The justice with which camus is concerned is a Christian concept. We learn in Ia Chute that the only honest juages are the Biblical ones in a painting the hero keeps locked in a closet, and they have 
been sent by God. Once again Camus is attracted by what attracts the Christian saint- divine justice. In the thira phase of Camus' evolution as a writer we rind the themes of love and of innocence. Through them the author again reveals an essentially Christian preoccupation; indeed, love and innocence are the basis of Christian doctrine. At the same time, he explores the nature of guilt, which, together with innocence, he seems to associate with the fall of the first man.

The temptation to strive for sainthood, then, is very strong for many of Camus' characters. While it does not imply the acceptance of a divine being, this temptation involves the practice of a morality very similar to that of the Christian saint, and the quest for an ultimate good in a universe where the values or good and evil have no meaning. 
REMERCIENENIS

La préparation de cette thèse doit beaucoup aux conseils et aux encouragements du Docteur C. Toloudis.

Je remercie également le Docteur $\mathrm{H}$. A. Waters, ainsi que le Docteur P. Viglionese de leurs aimables et utiles suggestions. 
INTRODUCTION • • • . . . . . . . .

CHAPITRE

I. IA MORT . . . . . . . . .

II. IA REVOLTE . . . . . . . .

III. IA SOIIDARITE . . . . . . . 30

IV. IA JUSTICE . . . . . . . . 43

V. L'AMOUR .............. 58

VI. I'INNOCENCE . . . . . . . . 74

CONCLUSION •................... 87

BIBIIOGRAPHIE •. • . . . . . . . . 95 


\section{INTRODUCTION}

Notre essai a pour sujet d'étudier la préoccupation morale a'Albert Camus dans son oeuvre littéraire. I'attitude qu'il présentait à la vie montrait une préoccupation qui dépassait les cadres politiques ou moraux de son époque. Sa recherche semble tendre vers quelque chose au-delà des problèmes courants. Il aspirait à une perfection morale avec une soif a'absolu si persistante que sa quête devenait presque un exercice spirituel dont le robile constant est ce que rous proposons a appeler "la tentation de la sainteté." Cet essai ne se veut aucunement exhaustif sur la question. Il prétend simplement mettre en valeur quelques manifestations caractéristiques d'une tendance dans la quête de Camus, tendance assez semblable à celle du saint chrétien.

Arin de mieux suivre la pensée morale de Camus, nous avons divisé notre essai en chapitres qui s'identifient aux grands thèmes camusiens. Ces derniers, de par l'importance que leur accorde l'auteur, marquent les points de départ et précisent plus ou moins l'orientation d'une dialectique. 
Cela nous a amenée à placer au déout de notre essai les thèmes où la préoccupation morale est moindre, comme ceux qui portent sur la mort et la révolte, pour aboutir aux thèmes qui se confondent avec les idées directrices de la sainteté, ainsi que l'amour et l'innocence.

En quoi les thèmes camusiens rappellent-ils les préoccupations du saint chrétien? Examinons brièvement ces thèmes.

Les hormes réagissent de différentes façons devant la rrort. Celle-ci peut être comprise comme la fin de la vie sur la terre. Elie peut également être vue coinme la porte qui mène au royaume, au mystère de I'homme, au mystère de Dieu. C'est ce dernier aspect que Canus semble adopter vis-à-vis de la mort. Non qu'il soit attiré par le mystère divin puisqu'il rejette Dieu; mais il reconnait un certain "sacré" à l'homme. Ce sacré est parfois appelé l'Absolu; parfois, on lui donne le nom de Vérité totale, Pureté totale, Intransigeance morale. Ia poursuite infinie de cet absolu mène toujours à la mort parce qu'elle dépasse les linites humaines. Fourtant, la pureté de cet univers est bien attirante. Canus s'efforce d'approcher du aomaine interdit et n'hésiterait pas à l'enfreindre 
si les consequences de u. rete n'étaicnt pas en contradiction avec sa phin..... je: faire face à l'absurde, ne pas s'abandonnex à I. ...t; mais aussi, savoir'l'afIronter quand il n'est lin possible de lui échapper. La mort, si elle est ur myen a'atteinare l'absolu, reste une tentation à combitre.

Il semble étrangé a'associer la notion de révolte à la sainteté. Cette impression disparaît quand on prend connaissance de ia définition que donne Camus de son homme révolté. Scion Camus, l'homme révolté ne I'est pas à la manière de sade, de Karamazov ou du surréaliste qui tire sur la we. Bien au contraire, il utent la vie de l'home a . e le bien le olus précieux gu puisse existom. Go... choi sa rérolte est-elle di-

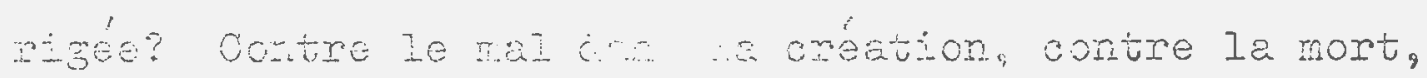
l'injustice; mais égalenent contre l'impureté des moyens utilisés par ceux qui poursuivent le même but que lui. Ainsi, lutte contre le nal extérieur, et le mal intérieur.

Quant aux autres trenes camusiens, les rapports entre la quéte morale co I'auteur et la sainteté chrétienne qui s'en décragra- sont beaucoup plus étroits et beaucoup plus chents. Cela s'applique à la solidarité, à la juśtì: à l'amour et plus particu- 
Iièrement, ̀̀ I'innocence. En effet, ces termes ont une résonnance bien chrëtienne. Jësus Christ est mort pour expier les péchés des hoinmes et leur, permettre d'être sauvés. Il a porté la croix, le fardeau des péchés, par amour des hommes. Les héros camusiens seront tentés par ce geste. Ils donneront leur vie pour que leurs firères humains vivent heureux et libres. Il n'y a pas de plus grand juge que Dieu, disent les saints. Et Camus d'ajouter: la vraie justice ne sera rendue que par ces Juges Intègres, ces envoyéa de Jehovah, granàs héros de la foi chrétienne gui peuplent le Iivre Saint. Pour atteinare la justice parfaite, iI faut être aussi pur que ceux qui symbolisent la àelivrance du mal.

A cette notion de la justice, viennent s'ajouter les concepts d'amour et d'innocence dont l'absence serait inconcevable dans un contexte chrétien. Pour atteinare I'intégrité des Juges, il faut être digne de l'Agneau mystique, ce grand symbole de l'innocence. Cela entraîne un don de soi, un amour des hommes total, accompagné de l'humilité Ia plus profonde. Ce qui revient à dire qu'il paut se dépouiller de tout ce qui nous empâche àe rejoindre l'innocence initiale. Il nous faut faire pénitence pour retrouver la pureté de 
l'enfant, I'innocence de l'Agneau, l'humilité et la générosité du fils de Dieu.

A cause de leurs connotations chrétiennes, les thèmes camusiens s'imposaient pour analyser le rapprochement entre la préoccupation de Camus et la sainteté. Nous voyons, avec chacun de ces thèmes, comment la pensée carnusienne se rapproche de la pensée chrétienne; comment ces thèmes sont inclus dans toute préoccupation morale de source chrétienne, puisque les notions d'humilitë, d'altruisme, d'endurance, d'cnour, se retrouvent chez le saint chrétien. 


\section{CIAPITRE I}

\section{LA MORT}

A tous ceux que l'absolu tente trop fort, la mort vient comme une réponse dérinitive. La plupart des héros camusiens ont dûu affronter, ou du moins rérléchir à la mort. Certains, comme Caligula, y ont vu le mal incamé de la créstion. D'autres, telle, Martha, s'en sont servis comme d'un motren utile; enfin, d'autres encore ne l'ont plus considérée comme une préoccupation majeure, et ceci est le cas de Tarrou. Pour tous, cependant, la mort est reliée, d'une façon ou d'une autre au mystère de la vie, le sacré que les hommes ne doivent pas approcher sans peine de périr. C'est la réaction des aifférents héros de Camus devant la mort que nous nous proposons d'étuảier.

Ie bonheur de Caligula a pris brutalement fin auanà ì a appris que "les hommes meurent et ils ne sont pas heureux."1 Cela signifie que ni la vie, ni I'amour, ni le bonheur n'étaient éternels. Tout ce à

$$
\text { 1Albert Camus, Calirula (Paris: Gallimard, }
$$

1958; Livre de Poche no. 1491), p. 27. 
quoi nous domons do ha? " "alouns ost paseager, et peut ćtre balayé par le roitraire de la mort.

Cela signipie que "tout, ....ur de moi, est mensonge ... "2 Affolé, bouleversé pan ce mureau systène de valeurs, Caligula pleure pour faire wre l'impossible, c'est-à-dire, faire vivre a bonheur humain:

Simplement, je me suir conti tout d'un coup un besoin d'impossible. choses, telles qu'elles sont, ne rne semblent setisfaisantes. . ... Ce monde, qu'il est fait, n'est pas supportable. anc besoin de la lune, ou du bonheur, ou de I'Amortalité, de quelque chose cui soit cener . -etre, mais qui ne sotit pes de ce ronde.

Ia mort a èté la revétat a jorporisie et du mensonge bu mone. Tonint a enjté totale et sachant c'ella ne cern pas, Cali la rajette cette vérité médiocre. Fervent de la poté totale, il n'est pas homme à se contenter d'une pureté relative. I'empereur romain va alors se mesurer avec ce qui a retiré le sens de la vie. Si ce en roi il avait foi n'est pas frai, "si la raison est menconge et hypocrisie, pourquoi la folie ne serait-ells pas vérité et pureté?"4

\section{Ioid.}

3IDid., p. 26 .

4pierre-Fenri Sirnon, résence de camus, La Lettre ot I'esprit (Bruxeiles: ponissance du Livre, 1961), D. 49. 
Juscue-là, la quête aésespérée ae Caligula pour la pureté fait de lui un assoiffé d'absolu digne a'admiration. Cependant, Caligula a réagi d'une façon trop extrême à la mort; oour dépasser la bêtise et la haine du sort, il se sert de ses propres armes: "J'ai pris le visage bête et incompréhensible des dieux."5 Ayant utilisé le pire aspect de la mort, cette injustice la plus criante, Caligula s'est détourné de la voie du pur. Son but était noble, sa révolte en faveur a'un monde pur s'aporoche de la recherche au saint. Cependant, I'empereur romain s'éloigne d'un chemin aussi cur à suivre en niant l'nomme, jusou'à en raire un objet.

Meursauit semble tout autant attiré par ce qu'il y a de plus pur dans le monde. I'univers dans lequel il vit, celui qu'il semble préférer, est un univers de Iumière totale. I'éclat qui se dégage de I'Etranger6 fait de cette oeuvre un monde limpide et transparent. Cette limpidité et cette transparence sont les éléments naturels à Meursauit; une journée à la plage le rend pIus heureux qu'une conversation creuse avec les hommes.

\footnotetext{
5camus, Caligula, ?. 101.

6Albert Camus, I'Etranger (Paris: Gallimara,
} 1942; Collection Soleil). 
Cet efret de la Iumière et du soleil exerce sur lui une forte attraction. C'est ce qui le conduit au crime. Cleude Vigée commente ainsi la description que donne Meursault de son geste meuririer: "C'est ce pas 'de trop', par lequel il s'aventure dans l'interdit, au lieu de lui faire échec par le regara, qui déclenche la catastrophe."7 Selon Vigée, ce pas "de trop" représente la nostalgie du sacré que l'on peut dégager de toute l'oeuvre camusienne, et que nous avons appelée tentation de I'absolu. En faisant ce pas, Mieursault a accomoli un acte de démesure. Cet acte, quelles que soient les conséquences qui n'allaient pas manquer de surgir, a permis à ieursault a'atteindre l'impossible, l'unité constituée par l'ardeur au soleil, la lumière, la mer. C'est parce gu'il voulait étreindre l'univers dans un geste qu'il a commis un sacrilége: il a "aétruit l'harmonie du jour,"8 il a porté atteinte à la nature elle-même. C'est pourquoi il mourra: "La mort est le prix de la démesure, même si celle-ci donne accès au monde de la réalité, et la démesure îut-elle, dans un cas d'aliénation extrême,

7Claude Vigée, "La Nostalgie du Sacré," dans Hommage à iloer Camus, ed. par Naurice Blanchot (Paris: Gallimard, 1957), p. 135.

8 Camus, I'trnamper, p. 88. 
La seule clé capable de rouvrir la porte du royaume patemel de la présence."9 Le désir de communier avec le sacré, le divin, est nécessaire. Mais puisque ce pèlerinage de l'absolu ne peut se faire sans effraction du monàe, Camus ne veut pas y céder. Vigée résume ainsi I'angoisse de Camus: "Comment apporter aux hommes le bonheur divin sans les condamner au même coup à la mort?:10

La passion de former une unité avec la nature et le vrai est rendue plus évidente au cours du procès. Meursault a été calomnié par bien des critiques, nais Camus Iui a renau justice: "Ioin qu'il soit privé de toute sensibilité, une passion profonde, parce que tenace, I'anime, la passion àe I'absolu et de la vérité.... Cn ne se tromperait pas beaucoup en lisant dans I'Itranger I'histoire d'un homme qui, sans aucune atiitude réroïque, accepte de mourir pour la vérité."11 Et c'est parce qu'il veut rester fidèle à la nature, à la vérité, à la franchise du soleil, que Meursault est conōamné. Comme l'écrit Robert Champigny, Meursault est un horme aui a maintenu en lui les vertus de l'en-

Svigée, "Ia Nostalgie du Sacré," p. 135. 10 Toid. pp. 135-136.

11 Albert Oamus, phéâtre, Récits, Nouvelles, Bibliothèque de la Pléiade (Paris: Gallimard, 1962), p. 1928. 
fance et "maintenir en soi les vertus de l'enfance et en éliminer les vices supoose une certaine réflexion et une ascèse."112 c'est volontairement que vieursault refuse de jouer le jeu de la société. Dans un monde où règnent l'hypocrisie et le mensonge, le choix de Meursaut est bien difficile à tenir. En effet, la société menacée dans sa sécurité le juge coupable. Meursault meurt en martyr àe la véritë.

Il en est de même pour Martha, la farouche héroine du Majentencu. 13 Celle-ci est à la recherche du borheur absolu. Elie ne peut le trouver dans Ie triste pays où elie vit. Les symboles au bonineur et àe la délivrance, de la beauté partaite, sont encore une fois le soleil, la lumière, la mer. Nartha rêve d'aller vivre dans les pays de la générosité: "Ah! mère! quand nous aurons amassé beaucoup à'argent et que nous pourrons quitter ces terres sans horizon, quand nous laisserons aerrière nous cette auberge et cette ville oluvieuse, et que nous oublierons ce pays d'ombre, le jour où nous serons enfin devant la mer àont j'ai tant rêvé, ce jour-là, vous me verrez sourire."14 Ia

12Rodert Champigny, Sur un héros paien, Les Essais XCIII (Paris: Galiinard, 1959), p. 48.

13 Albert Camus, Ie Malentenäu (Paris: Gallimard, 1958; Iivre de Poche no. 1491), p. 166.

14 IDIC. 
secheresse je ivartha se doit à ce rêve unique qu'elle poursuit, s'éloigner de la rẻalité sordide de sa ville si triste, voir la mer et le soleil libérateurs, chercher quelque chose àe pur enfin, l'absolu, hors a'un horizon médiocre. Ie crime de Martha contre son frère, donc contre la nature, a ét'e bien défini ainsi: "The munderous actions ... of a Martha are so violent an expression of revolt against the limitations of reality that ore c annot but see in them a deeper anguish and protest whose only check was the creative act itself."15

Ia passion de son frère Jan semble également tounnée vers le désir d'atteindre le bonheur. Non pas pour lui, car il esi combié, mais pour la rière et la soeur iadis abanonnées: "je suis venu ici apporter ma fontune et, si je le puis, du bonheur."16 Jan se fait un devoir ae partager son bonheur avec les siens. Pourtant, il semble que, comme le suggère Raymond Gay-Crosier:

Sans vraiment le savoir, Jan souffre aussi de la soif de l'absolu. A sa joie de vivre doit s'ajouter l'activitë humanitaire ain que le bonheur ouotidien soit rehaussé au niveau d'une satisfection morale. Ies aevoirs envers sa mère et I'amour du patrimoine ne sont que prétextes, ils jalonnent le chemin oui doit lé mener au bonheur

15Germaine Erée, Aloert Camus (New York ana Iondon: Coimbia University Press, 1964), p. 31.

${ }^{16}$ Canus, Ie Valentencu, p. 173. 
métephysique. Mais oui ait "métaphysique," chez Camus ait "absolu."177

Ainsi, le frère et la soeur, chacun de son côté, sont à la recherche de l'impossiole: Martha rêve de la pureté au soleil, Jan rêve a'être reconnu sans avoir à dire son nom, c'est-à-dire qu'il rêve a'un monde où une mère reconnait toujours son pilis, d'un monde où l'innocence et la pureté sont toujours reconnues. Comme le suggère Gay-Crosier, Jan est puni pour avoir aépassé certaines limites: "Le manque de sincérité, qui constitue la culpcoilité de Jan, ne consiste pas seulement en son cö̌t du démisement mais surtout en son infiaélité à soi-mềe, en I'absence a'une limite reconnue."18

Les justes, dans la pièce qui porte leur nom, 19 pensent égalenent à la création comme à une harmonie de la nature. Ils agissent au nom de cette harmonie et c'est pour cela qu'ils tuent. Ils veulent supprimer le tyran qui refuse que tous les hommes soient unis dans le bonheur, dans un esprit de justice et d'équité. Cette croyance à I'harmonie àe la création interdit que l'on porte atteinte à I'homme. Fourtant, le tyran opprime

17Raymond Gay-Crosier, "Les Invers d'un échec,

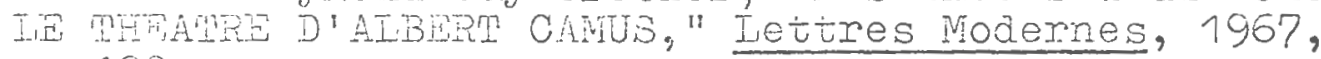
p. 120 .

18 Ibia.

19Albert Camus, I.es Justes (Paris: Gallimard, 1950). 
les homes. C'est donc le tyran que les justes vont tuer. Il n'en reste pas moins que ce tyran est un homre et que l'acte de justice est un crime. Incapables de surmonter cette angoissante contradiction, les justes offrent généreusement leur vie pour rétablir l'équilibre rompu. Voulant à tout prix que leur acte de justice reste pur, ils acceptent d'être les victimes de l'idée pure: "Camus, en exigeant que la révolte se justifie par l'échec et se purifie dans la mort, est plus tragique et plus généreux, et il accepte parfaitement les conséruences de ses orincipes, ou piutôt de leur contraatetion. 120

due reste-i-ij à Paire en race de la morí? La passion au sacré et àe l'absolu qui anime les personnages de Camus est difficile à réprimer, car elle représente Ie "royaume," ou encore, "I'endroit" de la vie. Ce royaume est la communion de I'être avec I'univers, l'union avec le soleil et la lumière, les noces mystiques avec la nature. Mais cette communion est accompagnée Le viojence et empiète sur la vie des autres. Elle représente ie moment de la vérité; mais cette dernière n'a pu être acquise qu'en dévastant tout autour de soi. Dans "La Ferme Adultère,"21 Janine, pendant un instant,

20Simon, Présence de Camus, p. 120.

21 albert Camus, "Ia Temme Adultère," dans I'Exil $\frac{\text { et ie Royaume (Paris: Gallimard, 1957; Livre de Poche }}{\text { no. } 1679 \text { ). }}$ 
a compris le mystère cu cosmos. Cette connaissance s'est Iaite a'une Iaçon violente: Janine était tombée, évanouie. Pourtant, comme la mort n'avait pas suivi le moment de la révélation, Janine ne peut considérer son expérience comre totale. Elle éprouvera le regret de son étreinte avec l'univers, sans toutefois le posséder. Pour jouin totalement de son expérience, il aurait fallu gu'elle soit anéantie.

C'est parce que la "révélation," ou la vérité, ne peut avoir lieu sans le sacrifice d'une vie humaine, gue comus consent à se plier. Mourir pour la vérité reste une fome de suicide. Caligula savait qu'il allait oérir, et il recinerchait méme la mort qui l'anéantirait, Iui et son beau rêve perdu. Nartha et Jan sont ésalement leurs propres victimes. Dans leur tragiaue et noble entêtement, tous deux ont refusé une vision olus humaine de la vie; Martha a refusé de voir dans son village autre chose qu'une tombe. Elle n'a pas essayé de se réconcilier avec le sombre aspect de son pays. Quant à Jan, il avait une trop grancie confiance àns la vie. Aveugle au mal, il a préféré croire que I'innocence est toujours victorieuse. Mous pourrions aire eutant de iveursault, pour qui la vie sans la vérité re peut être digne a'être vécue. Attituçe bien tentante que de mourir pour un idéal d'absolu et de 
pureté. Camus ne cède toutefois pas à cette tentation. Il sait que celle-ci a un efiet destructeur et c'est pour cela ou'il opte, bien à regret, pour l'attitude plus modeste de Sisyphe. Celui-ci ne considérera olus son rocher comme un signe d'oppression. Au contraire, parce qu'il sait que sa condamnation est éternelle, Sisyphe devient victorieux de l'absurde, "supérieur à son destin ... plus fort que son rocher."22 Il roulera son rocher, luttant ainsi pour sauvegarder la dignité des autres hommes. Nous conclu rons avec ces lignes de clave vìgée, qui résument varfaitement la lutte de Camis contre cette tentation à l'absolu:

$$
\text { ATec rostaigie et courage il se refusait }
$$
aux excès d'un sacré trop fascinant pour ne pas rons anéantin, arin ce persévérer simplement dans l'humain. Par-äelà la readition d'une vie ou'il défendait chèrenent contre la démesure splendiae du rout, Albert Camus n'a plus rien à crainare dœs piëges d'un royaume qui ressemblent si étrangement à ceux de l'exil.23

22Albert Camus, Ie Mythe ae Sisyphe, dans Essais, Bibliothècue de la Pleiace (Paris: Gallimard et Calmann-Lévy, 1965), p. 196.

23vigée, "La Nostalgie du Sacré," p. 142. 
La "pensée de miai" oui conclut I'Homme Révoltée a suscité les critiques les plus virulentes. Camus a été accusé par les existentialistes de se détourner des problèmes concrets qui faisaient rage vers ies années cirquante en raveur a'une certaine passivité. Ia noraie qui se dégage de Ia Feste n'était pas faite pour plake d tout le nonce. Tn efret, I'aspect qui a été Ie plue atracué est celui que certains ont qualifié ae non-intervention aans un monde où tous les homes se devaient de prendre position. Au moment où la bataille faisait rage, il devenait superflu de se contenter de ne pas être un porteur de germes. In Iait, cette attituảe a été dénoncée par Gaëtan Picon comme étant celle des hormes du XIX siècle, atititude qui a permis les catastrophes du siècle dernier.2

Un autre critique, Pierre-Henri Simon, commente

1Albert Camus, ilomme Révolté, dans Essais, Bibliothècue de Ia Pléiade (Paris: Gallimard et Oànann-Iévt, 1965).

2Cité par Philip Thody, dans AIBRRT CMMUS: a Study of His Work (Ionäon: Hamish Hamilton, 1957), 
ainsi Ia réaction ae Sartre devant I'Howne Révolté: "Pour Sertü, voir Ia situation présente du monde comme 'ie duel jmó̀oile de deux monstres abjects' et, par souci àe prreté morala, s'abstenir entre les deux, c'est choisin ia permanence cee la servitude."3 Ie reproche cui semole donc être commun à tous les critiques de Camus est que "Sisyphe Iäche ses compagnors co combat; il revient à la délectation de son merore solivaire et de sor effort noblement inutile;

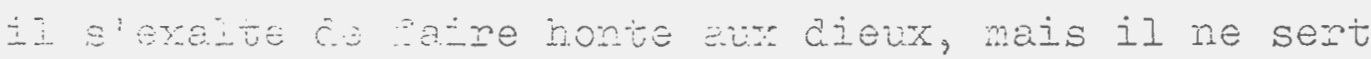

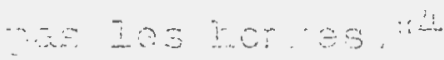

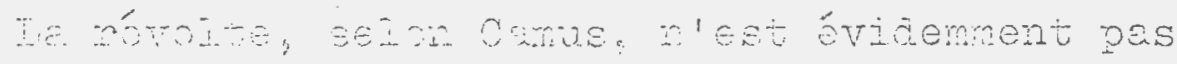
cewe ruit devant les responsabilités. Ie fait est que Io problème essentiel dédattu entre sartre et Camus concomait cette question éternelle: la fin justifie-t-elle ies moyenz: A cette question, Camus affirne cue pensone n'a le ároit de suporimer une vie d'some pour ur aventr incertain.

Le mourtre; quelies que soient les raisons invociées poun le jistitien, resue un meurtre, c'est-b-rine un atrentat corre une vie humaine. Camis re censere Samais de j'élever contre la violence.

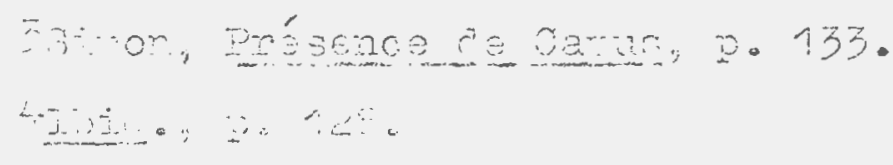


Dans un char itre intitulé "La Révolte historique," 5 il s'est penché sur tous ceux qui ont dûu afrronter I'assassinat. Ce mot n'est pas trop fort puisque tuer est un crime. Saint-Just avait voulu créer une cité àu pardon et de l'innocence. Pourtant, il avait fini autrement ou'il n'aurait voulu. Se mettant du côté de la justice, il s'est trouvé en train de proclamer la tyrannie. Pour atteindre son but, la violence lui était devenue nécessaire.

Il en est de même pour les révolutionnaires qui avaient la cause de varx. Celui-ci avait promis des "ierdemains qui chantent." Pour y arriver, il faliait passer sur le cadavre de tous ceux oui résistaient à cette vision future: "I'âge d'or renvoyé au bout de I'histoire et coíncidant, par un double attrait, avec une apocalypse, justifie donc tout."6 C'est cette justification ce la violence qui, la Dlupart au temps, engenore le meurtre, que camus rejette avec passion. Ia vie de I'homme est sacrée et rien ne peut justifier qu'on la supprime. Ainsi que I'a remaroué Simon:

Ia révolte camusienre est essentiellement une protestation contre Ie monae, élevée au nom des valeurs, c'est-à-dire qu'elle est, dans son fond, spirituelle et rationnelle

\section{5camus, I' Homme Révolté. EIbid., o. 612 .}


Blle est le refus de l'oppression, prononcé non seulement par amour de la justice et dans le respect- des moyens purs, mais à partir a'une situation concrète, et, sans référence à une eschatolosie prophétique.?

Refusant que I'homme devienne la proie de toute idéologie, religieuse ou historique, l'homme révolté de Camus exalte la vie humaine, refusant de la sacrifier à qui que ce soit.

Si Camus exalte la vie humaine avant tout, il insiste pour oue la révolte s'accompagne d'humilité. Retrapant I'historique de la révolte métaphysique, il reproche aux révoltés leur orgueil. Ces demiers se sont róvoltés au nom a'un absolu nui niait tout:

CeIui gui nie tout est autorisé à tuer, Sade, Ie dandy meurtrier, I'Unique impitoyable, Karamazov, les zélateurs du brigand déchaîné, le surréaliste qui tire cans la foule, revenciquent en sommé la liberté totale, le déploiement sans limites de l'orgueil humain. Ie nihilisme confond dans la même rage créateur et créatures.8

Reverdiquer la liberté totale signifie, à coup sûr, porter atteinte à la justice; tout comme la revendication d'une justice totale entraine I'empiètement sur la liberté. Camus s'oppose ainsi à tous ceux qui se réclanent de la révolte absolue. Il indique, cepen-

\section{Simon, Présence de Camus, p. 133. \\ 8camus, I'Homme Rérolté, p. 686.}


aant, que la révoite ajosolue peut avoir de la valeur: "II est bien vrai que la démesure peut être une sainteté, lorsqu'elle se forse de la folje de Nietzsche."9 Elle a encore de la valeur cuand elle accepte de s'anéantir comme c'est le cas pour Kaliayev; ainsi, "Ia vraie folie àe aémesure meurt ou crée sa propre mesure. Elle ne fait pas mourir les autres pour se créer un alibi."10 Après avoir suivi Camus dans sa démonstration de ce qu'est la fausse révolte, voyons ce qu'il propose sous I'appellation de "mesure" et de "pensée de midi." Contrairement à ce qu'affirment les critiques, l'homne révolté de Camus n'est pas un héros de la pasavizé. C'est un homme a'action, et qui prenci des riscues dars ses engagements, "parce qu'il ne cesse d'afitmer l'axigence a'un absolu de liberté et de justice et, en même temps, il refuse les angereuses sécurités policières, I'architecture protectrice d'un Etat dont il redoute la vocation oppressive."11 En efret, il est trop facile de se couvrir derrière les iitres ronflants a'une icéologie quelconque ou d'un autre système protecteur. Certains justifieront leur attituce oporessive en se référant à une nécessité historicue. Ia suppression de la justice ou de la

$$
\begin{aligned}
& \text { Ibid., p. } 703 . \\
& 10 \text { Ibid., p. } 704 . \\
& \text { 11Simon, Présence de Camus, p. } 131 .
\end{aligned}
$$


Iiberté, ou encore des deux à la lois, devient un étrange impëratif. Camus rejette ces entorses à l'absolu. Sa lutte se veut totalement dénuée de compromis et de justifications de crimes et d'oppression. Car.si la iustice a besoin a'être voilée pendant quelque temps, c'est qu'elle n'est plus la justice. Ce qui pousse également la révolte à l'action est son désir d'ordre. I'esclave qui se aresse contre son maitre exige que ce dernier le reconnaisse en tant qu'homme:

Si les hommes ne peuvent pas se rééérer à une valeur commune, reconnue par tous en chacun, alors l'homme est incomoréhensible à l'homme. Le rebelle exige aue cette valeur soit clairemenz reconnue en iui-même oarce du'il soupsone ou sait que, sans ce principe, le désorore et le crime régneraient sur le monde. Ie rouvement de révolte apparait chez Iui come une reverdication de clarté et a'unité. Ia rébellion la olus élémentaire exprime paradoxalement, I'aspiration à un ordre. 12 It cette aspiration à un oräre n'est autre chose que la nostalgie de l'unité, ou de l'absolu, que Camus exprime ainsi: "...étranges citoyens du monde, exilés dans leur oropre patrie. Sauf aux instants fulgurants de la plénitude, toute réalité est pour eux inachevée."13 Ie révolté camusien, luttant

$$
\begin{aligned}
& 12 \text { Camus, I' icomme Révolté, p. } 435 . \\
& 13 \text { Ibia., } 0.664 .
\end{aligned}
$$


pour zaine régrer un mone parfait, $n^{\prime}$ a pas souvent I'occasion de sentir son désir satispait. I'appel vers le borineus total, ae par son intransigeance, l'éloigne de ceux qui se contentent c'un bonieur relatif. Le but de l'homme révolté est humble. Ce à quoi il vise n'est que la revenáication de tout être normal: I'amour, le bonheur. Cependant, dars sa tentative de vivre heureux, il ne veut pas oublier les autres ni l'être à leurs dépens; sa révolte doit s'accompagner de ce que les chrétiens apoellent la charité: "Ce que Camus apoelle révolte, est la charité pour les chrétiens, avec sa double face de compassion individuelle et de fustice collective."14 Sa révolte sera également cette attitude honnéte ou'il procianait dans son Discours ae Sǘ̀e, vivant ainsi l'intégrité qu'il préchait dans son oeuvre littéraire. 15 son but est finalement la "passion pour la vérité." iais comment concilier cette soif a'un monde où règnent la vérité et l'amour, et du monde concret qui ne correspond aucunement à ces aspirations? Sa haine de la mort et de l'injustice lui défend absolument de toucher à l'être humain. It pourtant, il ne

14 corine Gacourek, Ies Innocents et les Coubables: Essaj d'exésée de l'oeuvre d'Albert Camus (The Hague: Nouton anc Co., 1963), p.63.

15 ilbert Canus, Discours de Suèòe, dans Essais. 
pevt s'emrecher de frómir en voyant les maux qu'il céenonce régner autour de iui. Sa première réaction est de s'opposer à ce qui empêche l'unité ảu monde en rendant le crime légitime. Cependant, il ne veut pas perare son innocence, il ne veut pas utiliser les mêmes armes que ce contre quoi il lutte. Cette tension pleine d'angoisse est celle des justes:

S'il tue Iui-meme, enfin, il acceptera la mort. Fidìle à ses oriorines, le révolté démontre dans le sacrifice que sa vraie liberté n'est pas à l'égara du mevrire, mais à l'égard de sa propre mot. Il cecourre en rrême temos I'honneur

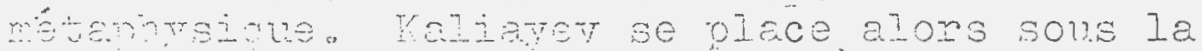
otance et ussine visiblenent, à tous ses Frones, le Itnite exante oú commence et finit I tomevir des homes.16

I:a réponse de xaijarev au meurtre cu'il a commis innocemment est certainement très noble. Cependant, si elie est àigne d'aāmiration, ce n'est pas elle que Camus choisirait. C'est plutot rarrou, ce révolté passionné, qui serait I'image parfaite de la révolte. Sachant que toute action-- quelles que soient ses intentions-- est toujours meurtrière, Tarrou s'est totalement retir'́ de I'arène de I'histoire. Cela ne simnifie pas ou'il est assuré de son innocence. Tiant cu'il sera en vie, il risquera toujours de se trovver au côté des bourreaux:

En tout cas, s'il ne peut pas toujours ne point tuer, directement ou inairectement, il peut 
metre sa fievre et sa passion à diminuer la chance du mourtre autcur de Iui. Sa seule vertu sera, plongé dans les ténèbres, de ne pas cécer à leur vertige obscur; encraîné au mal, de se trainer obstinément vers le bien.17

Tarrou scit que le nal ne vient pas toujours de I'extérieur. Ie mal existe àns l'homme et c'est pour cela que sa vie sera un ascétisme: il devra toujours raire attention à ne pas réveiller la peste qui se trouve en chacun de nous. Four ce raire, il se sacrifiera pour les autres, mais l'angoisse peroétuelle sera son lot. Tarrou reve de la paix qu'il a peraue quana il a anrits oue les homes se tuaient. Pour s'aporocher m peu de cette paix, Tarrou va se mettre du coté des victines: repusant ainsi ce orendre part à la "dégoûtente boucherie."18 II sait quelle entreprise difficile c'est de "faire le moins de mal possible et même parpois un peu de bien."19 comme le notait Rieux, "Tarrou avait vécu dans le déchirement et la contraaiction, il n'avait jamais connu l'espérance."20 Telle est la - -e du vrai révolté: le tourment qui surgitu du désir de ne pas tuer et la certitude que

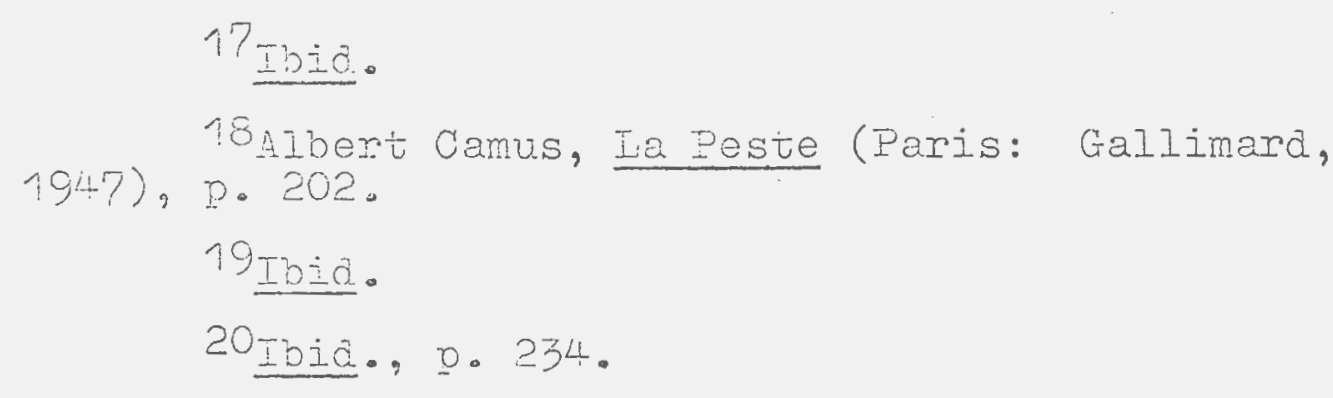


l'on ne pourra s'empêcher de le faire un jour.

Ia vraie révoite, selon camus, se révèle être ainsi à I'opposé des reproches que I'Homme Révolté a suscités. Ioin de se retirer de l'action, le révolté camusien se rait un devoir de s'y trouver au premier plan. Il lutte pour le bonheur humain, c'est-à-dire qu'il veut sauvegarder ses valeurs essentielles: l'amour, la dignité et la vie avant toute chose. Il refuse les transactions qui risquent de le rendre inficièie à lui-même. Ia révolte de Meursault face au prétre pourrait illustrer ce désir de rester intègre juscu'au bout. I'approche de la mort ne lui fera pas renier sa philosophie de la vie. Cependant, l'home révolté se heurte à des sentiments contraires: il se trouve race au meurtre, à la haine et à l'injustice. Voulant apoorter la paix, il vivra dans le déchirement, car il devra fournir un effort perpétuel pour ne pas tomber dans les excès. Cette philosophie de la mesure est ioin d'être médiocre. Serge Doubrovsky l'a ainsi dérinie:

In its evthonticity, Camus's "moderation" is cuite the antithesis of comfortable, mediocre roceration. It is a painful and perpetual effort. The true contact with being and with otners is not given. It can only be conquerea over the commonlace, over habit. The tenacious will to come to grips with the present is not easy to maintain when one knows just how easy 
it is to count on the futrae or the past for one's cm justificetion.?'i

I'où la tension oui accompane la révolte. Il s'agit de rester aux aguets, prét à détecter ses faiblesses, mais également orét à les assumer et, autant que possible, les corriger.

Il est intéressant de noter cette remarque de Simon au sujet du saint chrétien et de l'homme révolté de Camus:

Ie saint chrétien, Dossédé a'un désir a'unité, dans la discorde et àe permanence dans l'éohémère, combattant ie mal, la áeraison, I'injustice en lui et hors de lui et jetrant son défi à la rort: "mort, oi est ta victoire?", le, saint crnétien rumit ouelnues titres à représenter "Llhome revolte" " hans la figure du héros spirituel ou Camus inint par itixer son essence.22 D'aprìs ce comriontaire, la description gue Simon Iait du saint chrétien n'est pas très éloignée de l'attituảe au révolté camusien. Comme le saint chrétien, I'homme révolté désire le parfait amour. Pour y arriver, il s'arme de compassion pour venir en aide aux autres hommes. Notons touteiois que le saint chrétien

21 Serge Doubrovsiry, "rhe Ethics of Albert Camus," dans Camus: 4 Collection of Critical Essays, ed. par Germaine Brée (nnglewood Cliffs, New Jersey: Prentice-iall, Inc., 1962), p. 83.

22simon, Frésence de camus, p. 225. 
est notivé par I'assurance qu'il aşit pour l'amour de Diou, alors que le révolté de Camus reste au milieu des hommes. Le saint chrétien se donne à son Dieu. I'amour cu'il vorte à ce Dieu se trabuit en un amour pour tous Ies hommes. Pour servir Dieu, il servira donc les hommes; il combattra le mal comme étant ce qui est contraire à l'amour, donc à Dieu. Le révolté camusien, s'il utilise l'amour et la charité pour aider les hommes, ne le fait pas au nom d'une idée supérieure qui semait étrangèe à I'homme. Différent ae ceux qui ont Aatje I'hisoire ou a'une iáéologie politique un absolu, il oppose à ces derniers la pureté des moyens. Il ne cossera jamais ce lutter, nais il ne perara pas de vue l'homme: celui-ci ne sera pas l'objet de sacrifices au nom d'un avenir incertain. Plus proche du saint chrétien, bien qu'encore différent, I'homme révolté se montrera humble dans la tâche quotidienne. Il ne s'appuie sur aucune transcenaance pour justirier la fonce et l'oppression. Son cri sera de refuser d'utiliser l'injustice et le mal, tout en luttant contre eux. c'est de lé que provient a aéchirante contraâiction de la révolte camusienne. Eumble et honnête, terriblement exiceante, la quête àe l'homne révolté dépasse celle du poìticier come celle àe i'homme religieux. Le révolté comusien leur est supérieur car il refuse toute transac- 
tion avec I'impur ou I'inaction que l'un et I'autre justifieraient soit par I'nistoire, soit par la volonté de Dieu. Infin, la révolte est ce qui va au-delà à I'ancoisse humaine, et qui affirme une fois de plus les valeurs de I'homme dans un monde absurde. 
Nous avons vu, dans les chapitres précédents, ou'à la lutte solitaire de Sisyphe avait succédé la révolte passionnée du héros de Camus. Cependant, cette révolte ne concerne pas un seul individu. En écrivant "Je me révolte, donc nous scrnes, "1 Camus étend la révolte a tous ses freres humains. Au moment oir il écrivait Ia Peste, Camus s'était aéjà renâu compte que la neilieure pegon de lutter contre le mal et la mort Stait de tenäne la main aux autres hommes afin de lutter ensemble.

Pourquoi camus a-t-il décidé de se pencher vers les homnes? Il réponà à cette question dans ses Carnets: "Sens de mor oeuvre: tant a'hommes sont privés de la gräce. Comment vivre sans grâce? Il faut bien s'y mettre et Iaire ce que le Christianisme n'a jamais cait, s'occuper des damés."2 Ayant rejeté I'histoire

TCamus, I' ímme Révojté, p. 432. 2aIbert Camus, Carnets: janvier 1942-mans 1951,
Collection soleil (Paris: Gailimard, 1954), 2p. $129-130$. 
tout comme il avait rejeté Dieu, Camus va se consacrer à ceux cui ont besoin a'aiảe. Il prêche une morale de la panticipation où le salut individuel ne doit pas exister. Ainsi,

Ivan [Karamazov] incame le refus d'étre sauvé seul. II se solidarise avec les damnés et, à cause d'eux, refuse le ciel.... Il n'est pas ce selut possible pour qui sourire de la vráie compassion. 3

De mene, Rambert. Celui-ci avait combattu en Espagne, "du cotté des vaincus." 4 II avait appris alors que tout

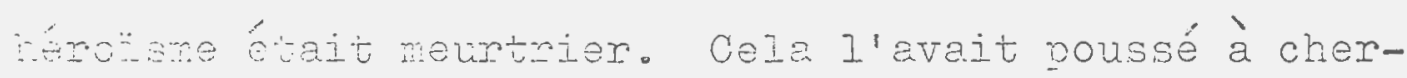
cken wo boneur personel. Kien ne valait une vie annire. pontont, Rarbent a chané a'avis. Il lui a sum be roje ce cu'il a vu pour comprendre cullil peut y avoir de la honte á étre heureux tout seuI." 5 II n'est pas nécessaire d'appartenir à un certain endroit pour s'en sentir solidaire; il suffit d'être un homule et de voir la sourfrance des autres hommes. Thomas Ianna a très bien exprimé le sentiment de I'homme camusien: "How could the rebel be happy when others suffer?"6

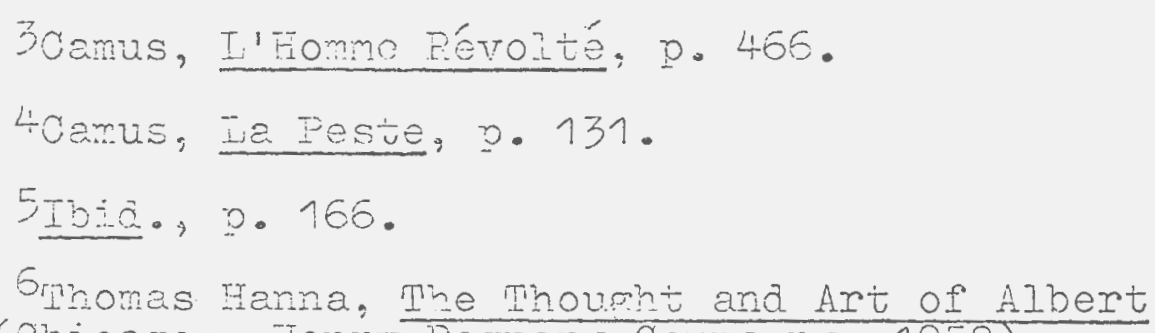


C'est justement ce sentiment de compassion envers la souffrance qui caractérise le héros camusien. Ie granả élan grì pousse Rieux vers Grand quand il apprend 1 e secret de ce dernier représente le lien qui unit tous les nommes. C'est à ce méme lien que Grand obéit sans murmurer quand on lui demande ses services contre l'éviảémie. D'une façon générale, la compassion s'accompagne d'une abaication de soì chez celui qui la ressent. Rieux s'est entierement donné aux hommes. Il ne se Iait cucune illusion sur la rie, mais il a décidé $\because$ antor a toutes ses forces contre la soufrance majie Sevjement, comne iarrou I'avajt Iait remargun d̀ kamoert, "s' $i l$ voulait partager le nalheur des hommes, il n'aurait plus jamais de temps pour le bonneur. il fallait choisir."7 Rieux avait choisi, et c'était son bonheur qui avait été sacrifié.

Une autre caractéristique de la solidaritée canusiene est Ie terme Pavori de Tarrou: la compréhension. Philio mody désinit ainsi ce not:

1 Hithout believire in God rarrou wishes to become a saint, to find inner veace in his "morale de la compréhension." phís phrase is aificult to transive. "Comoréhersior" has both the idea of understanding and of "comprenending" in the sense of including everything.8

TCamis, Ia Festa, p. 167.

8philio rnody, Albert Camus: 1913-1960 (New York: The vacmilian Company, 1961), p. 96. 
C'est cetie voie que Tarrou a choisi de suivre pour amriver à Ia sainteté: comprendre les hommes, et tenter a'mifier tous ces hommes dans un amour unique, assez senblable à celui de Dieu le père envers ses créatures. Se plaçant toujours du cóté àes victimes, il s'opposera au mal qui anéantit les hommes. "Ft moi aussi, je suis comme eux," s'exclame Tarrou, parlant des prisonniers de la peste. Ie lien fraternel qui le lie à ces hommes est indestructiole, car malgrè tout ce ae Itor weut leur reprocher, "il y a dans les hommes Dus ze choses à adniren que de choses à mépriser."10 remou choisit de se consacrer à eux. Comre l'écrit roper aricot, "ramou était de ceux gui ne trouvent jamais I'équilibre, nais qui font équilibre au mal."11 Que recherchent tous ces héros de la solidarité? Qu'est-ce qui les pousse à abandonner bonheur, amour pour se donner à I'homme et à sa souffrance? Pour Rieux, il s'agit d'un penchant pour ses semblables et a'une certaine honnéteté de conauite. A Rambert qui lui demandait ce qu'était l'honnêteté, Rieu répond:

\footnotetext{
Camus, I.a Feste, D. 98.

$10 \underline{\underline{I D} \pm \mathrm{C}}: \mathrm{D} \cdot 247$.

11Roger Ouiliot, Ia Ner et les Prisons: Essai sum dremt camus (Faris: Gallimard, 1956), p. 177 .
} 
"Je ne sais pas ce qu'elie est en général. Miais dans mon cas, je sais qu'elie consiste à paire mon métier."12 Pour les personnages des Justes, et plus particulièrement pour Kaliayev, cette force qui les pousse vers les hommes est bien olus que leur métier. Ce qui anime les justes, c'est bien sur "un peu de compassion pour la misère et la souffrance de tant de pauvres."13.

Kaliayev ressent les larmes et le sang de ses compatriotes comme une blessure personnelle. Mais il y a devantage:

Is nérclte des justes est une révolte íraternelle. IIs ce bettent vour le bonhem du nonse ot cherchent m rome rom a prónorve ies veleurs inciviauelles, en ganant injecte l'image qu'ils se sont faite

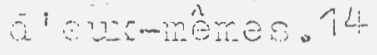

Noublions pas que Kaliayer utilise le mot "frères" pour parler à ses camarades. S'opposant à stepan, Kaliarer s'écrie: "Nous acceptons d'être criminels poun cue la terre se couvre enfin a'innocents."15 Can si ce n'était la pureté de l'idée, Kaliayev n'oserait jameis attenter `̀ la vie ae ses irères.

12cenvs, Ia peste, 0. 132.

13robert de Iupré, Alibert Camus (Paris: Temos Erésert, 1951), D. 84.

14ronck Jotterank, "Sur Ie Théâtre d'Albert Camus," äns Homare à Albert Camis, p. 119. 15camus, Ies Justes, D. 46. 
Coment Kaliayev conçoit-il I'humanité? S'il ost prêt de nounin, et s'il attenó la mort avec joie, c'est norce qu'eile lui semile la seule chose possible. N Guyen-Von-Tuy exolique ainsi la raison de cette attituce:

Ces héros [les iustes] s'identifient ainsi complètement avec la Eussie qu'ils se proposent de servir. Cet immense corps social fonctionne ici comme un "coros mystiaue," si I'on ose dire ainsi: ce n'est pas eux gui vivent et qui tuent, mais c'est Ia Russie opprimée qui vit et qui tue en eux.16

Cetite lutive ảans le groupe est la forme la plus élevée ce la comréhension. von seujement les justes Iutcentils poun I'anour absolu, mais ijs font corps avec le reste de I'numanité. Ceci explicue le désin de mourir de Kaziayev. Ii est certain que I'home quil a tué est un tyran, oppresseur de la Russie. rais il est aussi certain gu'il était également un homme. Cela est suffisant pour renare sa vie sacrée. Le meurtre de cet home, aussi justifiable soit-il, portera atteinte à "I'iāentité metaphysioue" de tous les hommes:

Comme tous les hommes sont un, le meurtre, quel gu'il soit, n'est pas seulement un fratricide, comme à l'étepe de l'union sociale, mais aussi

16Pierre N Guyen-Tar-Fu, Ia Nétaphysicue du

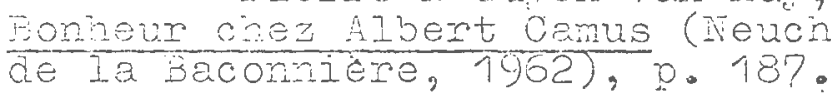


un suicide. Kaliayev accepte la mort pour lui-mêne, parce qu'il I'a connée à son semblabje, même si celui-ci est un tyran. 17 c'est ce que Camus a affimé oans I'Hornme Révolté:

Si nous re sommes pas, je ne suis pas, ainsi s'exnliauent l'infinie tristesse de Kaliayev et lé sìlence de śbint-Just .... Dès qu'il Inapne, le révoité coupe le monde en deüx. Il se aressait au nom de I'identité de I'homme avec I'home et il. sacrifie l'identité en consacranu, dans le sang, la différence. Son seul être, au coeur de Ja misère et de i'oporession, étàt alans cette iaentité.18

Avant brisé l'unité qui donnait ur sens à sa vie,

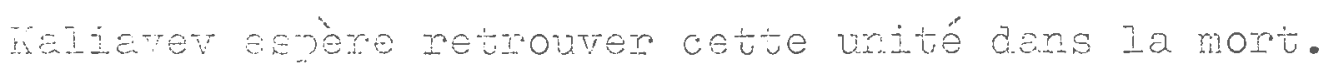
Gemaine rése exoliove ainsi la nature ae cette unité: "It is the sense of personai nesponsibility, not of guilt, which carries Kaliayev to a death worthy of a man; his self-respect is the force that gives him faith in his oneness with his group."19

Si Parrou dit que la raison de son dévouement est un áésir de paix, en iait, il ne recherche pas quelque chose ảe différent de Kaliayev. En effet, qu'est-ce que la paix de Marrou? Nous avons vu que pour amiver, larou a choisi ia "sympathie,"

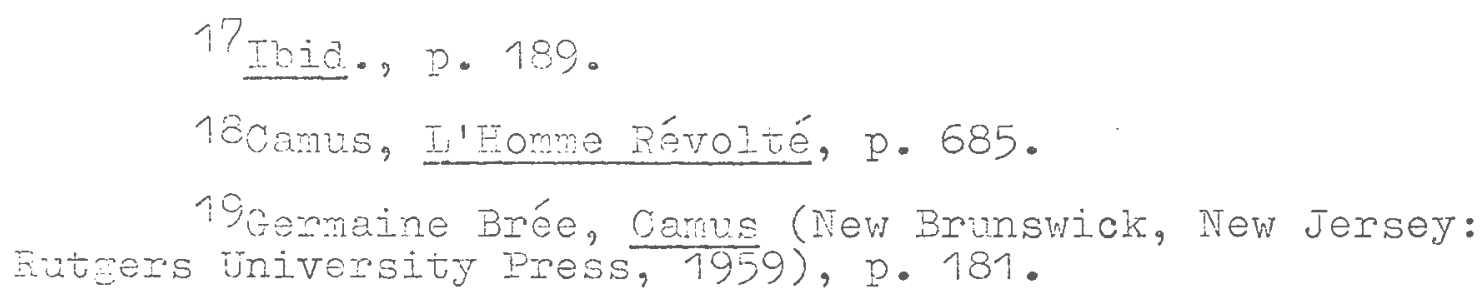




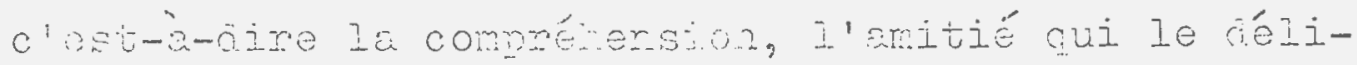
vremont de Ia pe:to, du mai. Comne pour Kaljeyev, ces sentinents ont pour but àe trouver un accord entre lui et ies hommes, et entre Iui-même et sa conscience. Cet accord, Tarrou cherchera à l'atteindre sa vie aurant:

Oui, j'ai continué d'avoir honte, j'ai appris cela, que nous étions tous aans la peste, et j'ai perâ la paix. Je la chercie encore aujourd'hui, essayant de les compreriare tous et de n'être l'enremi rontel de personine. Je sais seulement qu'il fant, faire ce qu'il iaut pour ne plus être mostipéré et que c'est là ce qui peut, seul, nous faire espérér la paix, ou une bchne mort à son céézutu. C'est cela gui peut soulager les hormes et, sinon les savver, du moins leur faire le noins de mal possible et même parfois un peu de bion... Je seis ... gue checun la porte en

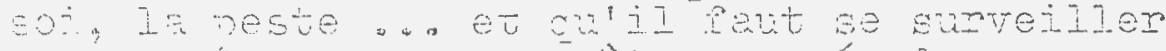

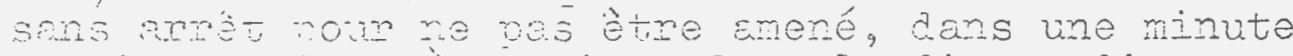

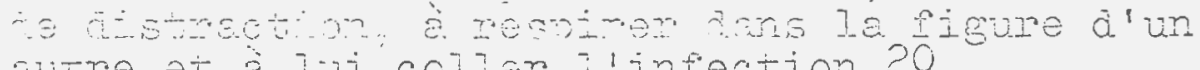
autre et a lui colier itinfection.20

Ainsi s'expime larmou qui avait comu le áchinerent et les contradictions a'un homme qui ne voulait pas être responsable de la mort de ses irères, quels que soient les motiss invoqiés, car toute atteinte à un autre inaividu l'empêcherait a'obtenir son propre pardon. Un Kaliayev assassin et en vie ne pourrait jamais se uardomer a'avoir violé cette loi humaine: la défense cu crime. Un Tarrou porteur de germes ne pourreit pas vivre non olus car il lui serait impos200amus, Ia Peste, po. 202-203. 
sible de se parânrer, c'est-à-dire a'atteindre l'union Spirituelle de sa conscierce avec la paix.

Ce même désir de réconciliation avec le monde et avec soi-mene se retrouve chez Jan, le malheureux eniant prodigue du Malentendu. Jan vivait heureux dans un pays de soleil et de joie. Pourtant, il lui manquait quelque chose: la réalisation de ce qu'il appelait son devoir a'homme, qui était de s'occuper de celies que le sort n'avait pas gâtées, sa mère et sa soeur: "Je vais essayer de ... mieux connẫtre celles que j'aime et a'aporenare à les rendre heureuses. ... Te veur retrouver ror pays, rendre heureux tous ceux are j'ajme."21 Comme l'écritu Roeren Quillot, "il poschati portune et boninens; il compromet tout cela par nolikanté poun cos demi-mortis que sont sa mère et sa soeur."22 Loin aes siens, Jan ne peut pas être tout à Pait heureux; il a besoin d'une "patrie," et le pays ou'il recherche n'est autre que la paix de Tarrou. Celle-ci aura le pouvoir de lui saire sentir que son exil loin de sa familie n'est plus qu'un souvenir, et c'est ce desir ae "réconciliation" qui l'a poussé vers

$$
\begin{aligned}
& \text { 21camus, Le Malentendu, po. 178-179. } \\
& \text { 220uiliot, La Mer et les Prisons, p. } 137 .
\end{aligned}
$$


ce sonire pays, encore une ftois, le désir de se pardonner.

Ie besoin d'une patrie est plus fort que la possession de sa richesse matérielle car la patrie lui donnera le sens qu'il appartient à un groupe d'individus, en loccurrence, sa famille. La tentative de Jan est un peu la lutte pour relier le lien ombilical, faire un avec les autres, retrouver l'unité de la nature. Pour cette réconciliation avec la nature, avec les autres, Jon est prềt à se dépouiller. II accepte de s'éloigner du bien surême, Ie soleil, et risove de perdre son amour. Wais ce qu'il veut, justement, c'est étendre cet amour pour sa ferme à sa familie, à l'humanitué. Il ne veut pius être heureux tout seul. Ia Patrie qu'il recherche n'est autre que la paix de l'âme. Et pour atteindre cette paix, il faut se dépouiller et se donner sans compter.

C'est encore le désir àe la réconciliation qui est Ia cause de I'angoisse de Daru dans "I'Hôte."23 L'instituteur Irençais vitu un profond arame. Comment se décartaser entre des hommes auxquels il se sent également attacké? S'il est proche des Français à canse de leur origine commune, il se sent aussi proche

23Albert Camus, "I "îte, dans I'Exil et le zoraume (Paris: Gallinara, 1957). 
res nebitants au désert. Comme Janine, la femre adultère, il a compris l'écho secret de ces homes secs et nerveux, irapnés par le vent et par le sable. Il ressent leur misère comme une blessure de sa chair.

Dourquoi faut-il cue ceux qu'il aime s'entredécinirent? Inconpris des uns et âes autres, il finira en martyr parce qu'il refuse de prenöre les armes contre ses freres.

Cet aspect de la solidarité vient compléter les dizérentes caractéristicues des héros camusiens, et qui se raprochent de cette dérinition au saini chrétien:

Te awint aide son prochain, il rayonne de cette "amotide" oui es au coeur d'un orand nombre

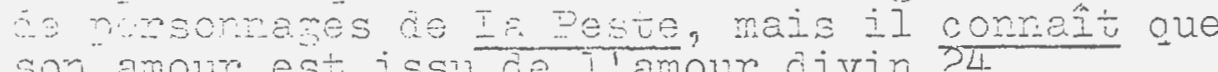
son amour est issu de I'amour divin.24

Martyr, le jeune Diego l'est aussi. Dans I'Itat de Siècee25 la ville de Caciix est sauvée grâce à la revolte de Diego. Il aurait pu fuir la ville pestiééée et choisir de vivre heureux avec Victoria. Seulement, comme Rambert, il aurait sans doute eu de la honte à être heureux tout seul. A son bonheur solitaire, ij a oréééré le saiut des hommes. Alors yue le vent de la liberté commence dejà à soufrier

\section{4 de Iuppé, Aloert Camus, p. 96.}

25Albert Camus, I'tuat de Siège (Faris: GalIimara, 1943). 
sum la ville, Diego aponjse. Il coit mourir, ayant accepté de prenare sur lui les péchés des habitants de Cajix. Minsi, Diego oaie àe sa vie le saiut des autres. Cepenōant, là où I'image du Christ se fait la olus irappante, c'est quana Ie héros de "Ia Pierre qui pousse, :26 d'Arrast, vient au secours du Coq. CeIui-ci a promis de porter une lourde pierre pour remercier Dieu de l'avoir sauvé de la fureur des eaux. Mais le Cog a trop dansé et le jour ae son éoreuve le trouve chancelant sous le poias de la pierre qui lui broie les épaules. C'est alors que d'Arrast bondit à son aide: "Il suffiti alors que le Noin désespéré lui jise 'pour que àmrast se substitue à iui, tei le Christ cui considéáa les races aivisées comme ure seuie race et voulut porter Ie farāeau au monde." 2 ? II est certain que ce Christ camusien se dirige vers la case du Coa au lieu de porter la pierre à l'église. Ce geste fraternel n'a d'autre but que de venir en aide à I'home et I'idée de Dieu lui est étrangère. Ies sentiments cui animent I'homme camusien à

26 Albert Camus, "Ia Fierre qui pousse," dans I:Txi et ie Royaume.

27Gadounek, Ies Innocents et les Coupabies, o. 221. 
I'éara des autres homes se nourissent d'une compassion toute chretienne. Gemus parle de "sioccuper des Gamrós," se chargeant ainsi de la mission des apôtres. Il aime les homes, leur scuffrance est la sienne et c'est au nom de l'identité mystique de l'humanité dans la couleur qu'il lutte. Sa révolte vise l'unité que les chrétiens accomplissent pour l'amour de Dieu, mais que Cemus atiribue à I'homme seul. Généreux parce qu'il n'attend aucune récompense de son action charitable, seule lo paix de l'âme l'intéresse. Son amour n'est pas exclucir; il se coit ’̀ tous ceux oui sourfrent. Sa réroite se pat an nom de tous contre un univers injuste. Pour de taire, eile

... ne peut se passer d'un étrange anour. ceux cui ne trouvent ie repos ni en Dieu ni en 'inistoire se conóanent à vivre pour ceux cui, comme eux, ne pevvent pas vivre: pour les numiliés. Le mouvenent le plus our de la révolte se courone alors du crì déchirant de Karamazov: s'ils ne sont pas tous sauvés, à quoi bon le salut d'un seuí!28

Supérieur au saint chrétien parce que plus généreux, l'homme camusien veut étendre le salut terrestre, c'est-à-aire le bonheur, à tous les homres. Ce salut aura lieu grâce à tous ceux qui, aspirant à un monde uni, se consacreront à I'humanité. 


\section{CAAPITRE IV}

\section{IA JUSTICE}

I'appel passionné pour la justice totale peut êre considéré comme un leitmotiv dans l'oeuvre de Camus. Cet appel n'est sans doute pas particulier à Camus, mais il fout avouer qu'il est le seul à avoir exigé que justice totale soit faite, et surtout, qu'elle soit Paite à I'aide de noyers purs, qui ne sacrifient en aucune façon le bonhew es la liberté de tous. jìćée qu'il avait ae Ia justice ure fois définie, Camus s'est aressé contre ce qui est habitueliement brandi sous ce nom. Ce sont ses multiples prises de position contre ce qu'il appelait injustice dans différents domaines qui l'ont opposé aux compromissions, faisant de lu̇ l'apotre ardent et austère de la justice.

Ie premien cri que lance Camus contre l'injustice est celui de 1 'indignation causee par la chair et l'esprit meurtris. Ce cri dénonce la création elle-même. Pourquoi? Camus n'a jamais voulu accepter la soufrrance qui régne dans le monde parce qu'il n'y avait rier poun la justifier. A ceux cui lui opposent la 
volonté d'ur Dieu puissant et omniscient, Camus répond en dénongant le catholicisme conme une doctrine de I'injustice. Le Christ lui-même n'a-t-il pas sourfert de I'injustice des hommes? La plaidoirie de Camus contre l'injustice de la création se manifeste de facon très émouvante dans le dialogue qui suit la mort du fils du juge Othon. Se retowrnant brusquement vers celui qui acceptait la peste comme un châtiment du ciel, Rieux s'écrie: "An! Celui-là, au moins, était innocent, vous le savez bien!"1 Cepenōant, meme si Paneloux acimet I'inccence de ceriains êtres iumains, il refuse de se révoltez contre le mal qui les accable: "Cela est révoltant parce que cela dépasse notre mesure. Mais peut-étre devons-nous aimer ce que nous ne pouvons pas comprendre."2 Cette attitude est violemment rejetée par Rieux-- et Camus-- pour qui la souffrance non expliquée ne peut, et ne doit pas, être justifiée: "ion, mon père, dit-il. Je me fais une autre iáée de l'amour. Et je refuserai jusqu'à la mort a'aimer cette création où des enfants sont torturés."3 le défaut de la création-- d'où, son in-

1Camus, La Peste, p. 174.

2Ioid.

3 Inid. 
justice-- est de permettre que l'innocence souffre et que son mal ne soit pas justifié. Le cri de Carnus est donc un appel conảamné à rester sans réponse puisqu'il arfirme que le ciel est vida. Il n'y a pas de Dieu. ivais même s'il y en avait un, ce serait un Dieu injuste. Iutions done contre l'aveuglement de l'univers, avec passion et sans relêche.

\section{I'Iomme Révolté pourrait être lu comme une}

longue protestation contre les différentes justifications de ce que cemus appelle meurtre. Il croit très fort au daoit des horres de se révolter contre un oräre injuste, ot critroe être en faveur de l'action salvetrico. Pourtant-- et c'est là que la quéte de Camus mortre toute sch intransigeance et toute sa pureté-iI re peut s'empêcher àe dénoncer le crime qui accompagne, trop souvent, hélas, les efforts vers un monde meilLeur.

Camus élève a'abord la voix pour dénoncer ceux qui suivent leur pays à I'aveuglette, qu'il soit dans le vrai ou dans le faux. Ies nazis prétendaient changer l'ordre cu monde. Fassacrant d'une façon arbitraire, is ont invoqué le besoin de l'orare. Dans cette attitude, oamus n'a vu que le désir de conquéte, ae suojuguer des peuples en les faisant ployer sous l'in- 
justice:

C'est pourquoi, si profondément décidés que nous soyors juste, il faut savoir aussi que nous sommes déterminés à rejeter pour toujours la célèbre phrase dun iaux grand home et à décjarer que nous prérérerons eterneliement le désordre à I'injustice.4

Chaque indiviau doit se faire une obligation de dénoncer son pays si celui-ci est prêt à commettre l'injustice. Les considérations d'ordre national ne doivent pas entrer dans un tel débat:

Non, vous disais-je, je ne puis croire qu'il faille tout asservir au but que I'on poursuit. Il est des mojens qui ne s'excusent pas. Et

je voudrais pouvoir aimer mon pays tout en aimant la iustice. Je ne veux pas pour lui de n'importe cuelze grander, thtwce celle du sarg et du mensonge. C'est en laisant vivre la justice que je veux le faire vivae.5

Di ia justice proclamée par un pays passe sur la pureté uu but envisagé et des mojens utilisés, sì elle cesse de s'appuyer sur le caractère moral au nom duquel eile lutie, aiors, il raut la dénoncer comme injuste. I'amour de la patrie, aussi fort soit-il, ne passera qu'au Qeuxième plan, après l'exigence de la justice totale.

La nêre quête de pureté dans la justice se re-

5Albert Camus, "Actuelles I," dans Essais, p. 277.

6ilbert Camus, Iettres à un ami allemand, dans Essais, p. 221. 
trouve dans les passages consacrés aux difiérents révoiutionnaires, en particulier ceux qui se réclament des justiciers. Saint-Just, Stepan, les révolutionnaires soviétiques, tous ces passionnés de la justice devraient susciter I'admiration. Si Camus apprécie hautement la pureté de leurs motifs, il ne peut approviver les moyens qu'ils utilisent. Il est bon de lutter pour la justice, mais "la justice meurt dès l'instant où elle cevient un confort, où elle cesse a'être une brûlure, et un effort sur soi-même." 6 Strpan veut très sincérement que les enfants de la Rusíe ne soient plus écrasés sous le joug arbitraire du Grand-Duc. Mais son róle aevient trés facile à remplir s'il lui sufrit a'éliminer tous les ennemis de la justice, c'est-à-dire ceux qui n'approuvent pas ses mojens. Ce qu'il îudrait que Stepan fasse pour ne pas perdre son but de vue, c'est de s'interroger constamment s'il oeuvre toujours pour la justice. Sa vie doit être une tension permanente; l'angoisse doit la remplir car il ne pourra jamais être sûr de ne pas abuser de sa mission. Il risquera toujours de tomber aans la fracilité. Cet erfort sur soi-même que prêche Cemus se révele ure véritable ascèse: se surveilier

\footnotetext{
6Albert Camus, "Actuelles II: Chroniques 1948-1953," dans Essais, p. 721.
} 
constamment pour ne pas commettre I'injustice que I'on est en train ce combattre. Ainsi, l'existence du justicier est a'aborà une exigence exercée sur Iui-neme. Il luttera sur àeux fronts: il combattra le mal, I'injustice extérieure à lui, mais le plus difîcile sera de venir à bout, d'une façon definitive, de l'injustice intérieure. Voilà pourquoi l'équilibre parfait est si difficile à atteindre, et une fois atteint, si précaire.

Ia facilité, donc I'injustice, peut provenir de ce que I'on remet le règne de la justice à l'avenir. Centains théoriciens essayent de nous convaincre qu'il est nécessaire de suppimer la liberté pendant un cervain temps, pour permettre un épanouissenent éventuel. Er autercant, il paut soupirir l'esclavage et la mort. Gamus répond par son désir noble et impossibie: il faut avoir iiberté et justice en mêne temps. Aucun des jeux éiéments ne peut être sacrifié à l'autre sans porter atteinte à la dignité de I'homme. C'est la justice sans compromissions pour laquelle Camus se bat. C'est la justice iâéale, entourée de son auréole àe purete intrarsigeante que camus vouarait faire vivre. II existe pourtant des situations où I'homme doit tuer s'il veut survivre. Camus pense à l'esclave. 
Si celui-ci ne se revolte pas, il n'existera jamais puisque son maítre ne le reconnầtra pas en tant qu'individu. Pour rétablir la justice, il faut que le maître qui refuse d'entendre raison soit supprimé. Dans ce cas, si l'esclave a raison de se revolter, Camus ne peut lui àonner raison jusqu'au bout, car le meurtre reste le meurtre. Canus rêve de la justice qui ne fait pas couler le sang. Cependant, puisque de telles situations ne peuvent être évitées, alors, que notre mort suive celle de notre victime. C'est la seule attitude qui permette que la justice ne se óparte pas de la pureté qui lui est propre. Ainsi s'explique I'action des justes. Ies révolutionnaires russes luttent pour que la Russie vive libre sous un régime juste. Sachart que le tyran $r^{\prime}$ acceptera pas de faire régner la justice, ils ont choisi, comme situation extrêne, d'utiliser la terreur pour améliorer le sort des hommes. Mais il ne suffit pas de tuer. Ies justes savent que tuer est un acte injuste. Déchirés entre leur lutte pour la justice, mais angoissés de perare leur pureté, les justes orfrent leur vie pour consituer un équiliore à l'injustice commise. En donnant la mort, ils se sont rendus injustes; en donnant leur vie, ils ont sauvegaraé leur innocence: "Ils 
avaient choisi I'action et la terreur pour servir la justice, mais ils avaient choisi en même temps de mourir, de payer une vie par une vie, pour que la justice àmeure vivante."7 II est évicaent qu'une telle attitude est impraticable. Que doit Iaire le révolutionnaire animé par la foi d'un nonde meilleur, et convaincu que I'avènement de ce monde n'aura lieu que par la violence?

En exigeant la justice absolue, Camus s'éloigne des possibilités hunaines. Ce qu'il réclane est bien Euderous des guerejies politiques. II a été critiqué pour ne pas cvoir accepté une justice relative, plus adéguate à I'histoire et aur hommes, et qui tienarait compte d'un certain réalisme politique. Mais ces critiques n'ont pas empêche l'admiration; comment ne pas admirer celui qui "dit le vrai ... rend la justice oppose à tous, à chaque instant, le fait moral à l'état brut"lo se plaçant au-dessus des nécessités politiques, Il exige que la justice totale soit rendue. Camus a passé sa vie à réclamer que nos actions ne s'éloignent janais de la morale, c'est-à-äire, le respect de la vie nuneire, ia préservation à la pureté dans la justice.

\section{TIOio.}

George Eourdin, Canus Ie Juste (Paris: Les Eaitions cu Cerf, 1960), p. 91. 
C'est pour ces raisons qu'il va s'oposer violemment a ceur qui foulent ces valeurs au nom d'une certaine justice.

La cible de Camus est la justice consacree, celle des tribunaux. Camus n'aime pas les juges. Ils sont ceux qui prononcent les condamnations à mort, ceux qui permettent qu'une vie d'home soit supprimée, et cela pour àes raisons qui ne sont pas nécessairement celles de la justice. Dans les tribunaux, Ies juges condamnent ceux qui re sa conforment pas à ce que la socíeté consiàre comne juste. C Cest sous cette couleur qu'il sut exemirar la concamaticn de Meursant. Ie héros do 마. come ur houre juste. Dars ses parozes comme dans ses gestes, Meursault refuse de se laisser aller à juger a'une facon absolue. Ainsi, il rapporte un commentaire de Céleste au sujet du chien de Salamano: "II y a huit ans que cela dure. Céleste dit toujours que c'est 'malheureux,' mais au fond, personne ne peut savoir."9 Meursault ne se laisse pas influencer par les ozintons qui coument sur le compte de Raymond sintès:

Dane le quartier, on dit qu'il vit des femmes. Girind an Iui demande son métier, pourtant, il est "magasirier." In général, il n'est guère

9camus, I:Evranger, 0.43. 
aime. Mais il me parle souvent .... Je trouve ce qu'il dit intéressant. D'ailleurs, je n'ai aucune raison de ne pas lui parler.10

Enfin, il rait preuve de robles sentiments quand il conseille à Raymond de ne pas attaquer son adversaire en lâche: "Il ne t'a pas encore parlé. Ça ferait vilain de tirer comme ga."11 Et plus loin, il ajoute: "Prends-le a"homme à home et donne-moi ton revolver."12 Meursault connầt donc ce qui est juste et se conduit seion la règle de la justice. C'est parce qu'il vit et parie seion la véritable justice que Memsault est oñuné:

İÉ ̀े cor imncenco. c'est en effet cet amour de

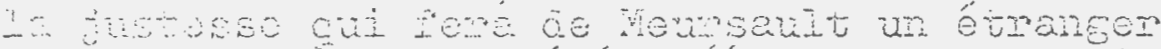
par rapory à la société théátrale. Pranchise, iroartìts padene, courage, le réctt de vieursauit s'élève dans me souveraine dignité. Cette dignité est étrarge, elle est étrangère à Ia société théâtrale. Cette dignité de I'animal qui a le langage s'oppose à l'hypocrisie du conéaien et l'inquiète. C'est en cela, essentiellement, que Meursault sera reconnu coupable.13

Le juge Casacio n'obe'it pas à la loi parce qu'elle représente la justice, mais parce qu'elle a été consacrée loi. Il condamnera àone l'accusé si celui-ci

$$
\begin{aligned}
& \text { 10Ibia., D. } 44 . \\
& \text { 11 Ivid.9. } 83 \text {. } \\
& \text { 12IDid. D. } 84 . \\
& 13 \text { Chanpigny, Sur un héros paien, p. } 92 .
\end{aligned}
$$


ne suit pas les règles établies, mêre si elles ne reposent pas sur la justice: "Je ne sers pas la loi pour ce qu'elle ait, mais parce qu'elle est la loi."14 "Vais si la loi est le crime?"15 répond Diego; "Si le crime devient la loi, il cesse a'être crime."16 Ia justice rendue dans les tribunaux n'est donc qu'une hideuse mascarade, indigne du nom de justice. Elle est piutot le nom que l'on conne à la vengeance. Ia concamation portée par les juges représente la vengaence d'une socíeté meracée dans sa sécurité, dans son hyocuisio. ciest ce que camus dénonce dans ses "retiexiono sur la Guiliouino."17

Le prétexte dénoncé aans cet ouvrage est celui de l'exemplarité. Si cela était vrai, pourquoi les executions ont-elles lieu dans le plus grana secret? Non, il s'agit simplement ce vengeance, attitude d'autant pius injuste que "... personne parmi nous ne peut s'ériger en juge absolu, et prononcer l'élimination áfinitive du pire des coupables, puisque nul

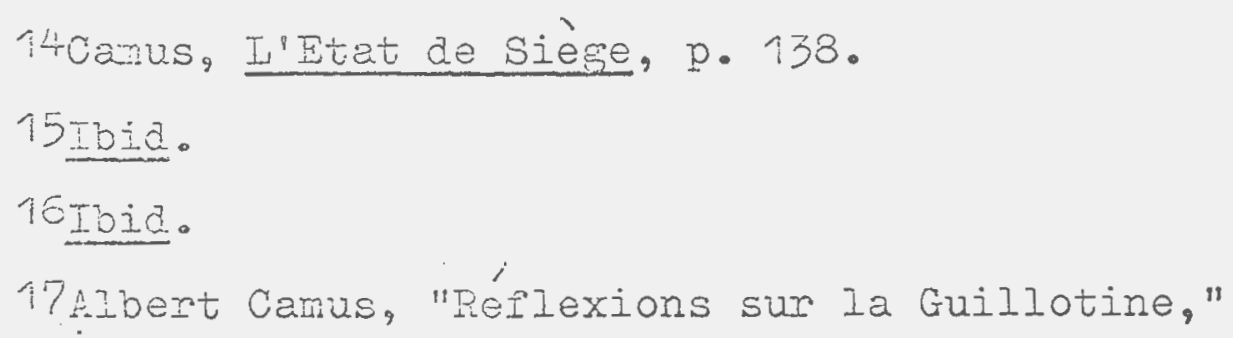

17Albert Camus, "Réliexions sur la Guillotine," árs Essais. 
d'entre nous ne peut prétenare à I'innocence absolue."18 Ces paroles rejoignent le plaidoyer de Clamence qui ne veut plus juger parce qu'il a perảu l'innocence qui lui permettait de le raira. ivous ne pouvons parler de justice si elle se sépare à l'innocence. "Et que seraiti, demenàe haliayev, la justice séparée de l'innocence?"î Ayant áécouvert que la justice qu'iI dérendait n'était plus innocente, Clanence s'instaure juge-pénitent. Il s'est rendu compte qu'au moment de ses piaidoiries les plus passionnées, il ne vivait pas seion ce qu'il prêchait. Il dérendait une certaine idéo, accusait d'autres de ne pas vivre conformément à ostô idée, et nétuit Iui-nême que le miroir déformé de la vérucíle justice. Pour avoir, de nouveau, le droit de parler au nori de la justice, Clanence se fait pénitent. Il s'accuse de ne pas avoir vécu seion la véritable morale. Il lui faut s'accuser, reconnaître son hypocrisie passée pour atteindre l'intégrité de la justice: celie-ci ne peut pas exister sans l'innocence. Etant tous coupables, comment pourcions-nous prétendre juger les autres? ITous ne pouvons que rendre des jugements relatifs et iutter en nous-même, pour ne pas

$$
\begin{aligned}
& \text { 18 Ibiö. pp. 1055-1056. } \\
& \text { 19camus, Ies Justes, p. } 46 .
\end{aligned}
$$


attraper le microbe de la peste. Il est si facile de s'oublier... Dans un univers où le jugement de l'Autre est roi, Camus demande que chaque juge soit d'aborã son propre juge, c'est-à-aire qu'il se fasse pénitent. Il demande que l'on s'accuse avant d'accuser les autres, et que notre innocence puisse être évidente à tous. In fait, ce que Camus recherche, c'est le juge parfaitement intègre qui n'a rien à se reprocher, l'homme ideal enfin!

Ces juges parraitenent intègres existent. Walhevreusement, ils sort enpenés. It Clamence de nous dononter que la justice parovite est morte à jamais. Il possede, enfermó chez iui, un tableau célébre représentant les Juges Intègres allant à la rencontre de l'Agneau mystique. Eclatant d'un triomphe amer, clamence nous présente cette preuve de l'impossibilité de la justice: les vrais justiciers, ceux que Jéhovah a envoyés pour sauver Israel, les Juges partis à la rencontre de l'innocence, sont enfermés. Ceci est la preuve incontestable que les hormes sont abandonnés à la fausse justice, celle qui est dérinitivement séparée de I'innocence.

En quoi la notion de justice que dérend Camus se àstingue de ce qui est habitueliement désigné sous 
ce nom? La justice, selon Camus, est un cri perpétuel et puissant contre tout ce qui fait fi des valeurs humaines. Il refuse absolument àe reconnaitre l'injustice de la création come un châtiment divin car il croit à une certaine innocence de l'homme. Il est impossible a'accepter que la mort à'un enfant soit le prix de cette justice. Ca qui justifie la mort d'un être humain ne peut être la justice. Camus s'elève également contre la justice qui se sépare de la liberté. Cette demière ne pelit avoir comme nom que tyrannie et oppression. Ie plein épanouissement de la justice n'a lier cue lorsqu'entiène expression est accordée aux romes. Loin a'etre un joug à raire subir aux homres, la justice semie devoir posséder les vertus des Juges Intègres, à savoir l'innocence du but et des moyens, ainsi qu'un pouvoir de salut d'origine quasi-divine. La justice parfaite est ce qui nous sauve âu mal. Mal exténieur à nous, mais aussi intérieur. Encore une fois, la quête de Camus semble trouver sa réoonse dars l'univers chrétien. Ia seule justice cui lui panaisse honcrable semble la justice divine. Compe pour les autres éléments de sa préoccupation, la notion de la justice selon Camus appartient à un domaine 
mysticie, olus rrand et plus pur que tout ce que I'homme peut approcher, mais vers lequel il ne cesse de tenare. 


\section{GEAPITRE $V$}

\section{I'AIOUR}

La notion ce l'amour qui se dégage de l'oeuvre de Camus ne laisse pas de frapper par la sobriété avec laquelie elle est traitée. Ce n'est pas l'aspect sensationnel de I'anour qui attire son attention, mais le côté silencieux, Ia rencontre intime qui permet l'union totale. C'est I'amour généreux de ia mère pour son enand, et l'anour de l'enfant pour la mène sage et silen-

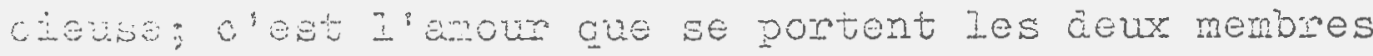
au couple: enfin, c'est cette tendresse afpectueuse et forte, I'anitié profonde. Si Camus ne reconnast pas à l'amour l'effet sensationnel qui lui est souvent attrioué, c'est parce que, comme toute chose de ce monde absurảe, I'amour n'est pas destiné à être éternel. Toutefois, il reste le moyen d'atteinare un meilleur monde, celui du "royaume," c'est-à-dire l'univers de la paix et de la réccnciliation. Si Camus choisit de prérérence les qualités spirituelies de l'amour, c'est parce qu'elies sont la voie la plus sùre vers la paix.

La première tendresse que le jeure Camus rencontre est̀ celle de sa nère. Evrange forme d'anour que celle 
qui unissait la mère et I'enfant! Jusqu'à un âge très avancé, Camus ne perd pas le souvenir de la tenäresse si peu démonstrative qu'ils se portaient. Les mots ne leur étaient pas nécessaires. A quoi bon les paroles puisqu'ils pouvaient communiquer avec leurs coeurs? Ils appartenaient à la même terre et formaient corps avec la nature. Leurs âmes se confonaaient et étaient comme dans une commurion éternelle. Qu'aurait-elle à aire, cette mère? Rien, puisqu'elle possédait tout ce qu'elle désirait: son bonheur était face à elle, ảans le visage de son Iils. Ils n'cnt pas besoin de paroles pour se comproncre oar ils ont parié le méme langage. Ia mèe a portó sor errant, elie a respiré avec lui. I'ensent, après quij aura grandi, gardera toujours le lien spirituel de celle qui l'a mis au monde. Ia force de ce Iien est telle que Canus relate ainsi la veillée auprès de sa nère malade:

Ce r'est que plus terd qu'il éprouva combien ils avaient été seulz en cette nuit. Seuls cpntre tous. Les "autres" domaient, à I'heure ou tous deux respiraient la fièvre. ... Rien n'existait plus .... Rien que la maladie et la nort... - Plus tera, bien plus tard, il devait so souvenir de cette odeur nếée de sueur et de vinaigre, de ce momert ol il avait senti les liens qui l'attachaient à sa mère.1

1Albert Camus, IEnvers et l'Enaroit, dans Essais, 
Ie ton de ce passage pourrait étre de mise dans la description de ia naissance. Ia souffrance de la mère est en mêne temps celle de l'erfant, qui s'içentifie à la meine, ressentant le hai comre dans sa propre chair. ciest ce caractère a'union aussi parfaite qui constitue I'unicité de I'amour maternel et̀ de l'amour filial selon Canis. Qui, en dehors au contemplatif, atteint un tel degré d'identirication avec une autre personne? Il s'agit d'une fusion, degré d'anour où les paroles ne sont plus récessaires, oi le puissance du lien n'est rendue évarte cue par les récctions viscéraies des partenatses devent la sourfpance ou le borhour de l'Autre. Le sentinent qui wit la mère et le fils est total, pareait, et constitue le degré ultime de la sagesse. Neursauit, bien après la mort àe sa mère, a compris le message secret qu'elle lui envoyait. Iui-nême au seuil de la mort, il ne perd sa sérénité. Il pense à la vieillesse de sa mère et la mort ne lui fait pius peur:

Pour Ia premiere fois depuis bien longtemps, j'ai pensé à ianan. II $m^{\prime a}$ sernolé que je comprenais pourouoi a la fin c'une vie elle avait pis un

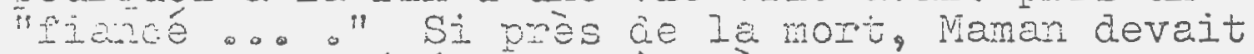
s'y scruir libérée è prôtre a tout revivre. Persone, perconine $n^{8}$ avait le aroit de pleurer sis $\operatorname{lil} 0_{0}$

$$
\text { 2Canus, I'Etranger, p. } 171 \text {. }
$$


Monscuitu a compris la segesse de sa hare. La mort peut wettre fin à la vie, mais il ne faut pas se rendre。 La İbération àe la mère Iui a appris comment vaincre la peur de mourir et c'est pourquoi veursaut va affronter Ia mont dans la sérérité. Au-delà de la tombe, la mère a céussi à transüetire le message du salut.

II en est de même pour Ie héros du Malentendu. Si Jan n'a pas vouiu se faire reconnaitre, c'est parce qu'il avait foi cans l'amour maternel. Il croyait que cet amour serait plus fort que l'absence, plus fort cue le nal, et c'est en erret ainsi que nous le décowmons par I'intermédiaire de Mre Rieur. Ce que

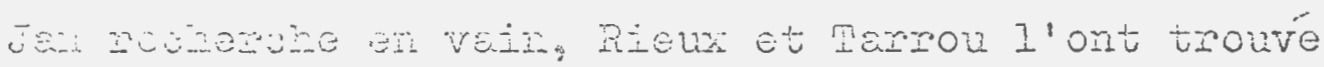
danj lan newe. I quoj est due la porce de I'anour maternez? IT Guyen-Ten-Iúg répond:

Uriversel et inconditionnel, äésintéressé et altruiste, actif et rajeur, I'amour raternel est donc la seule forme d'amour qui puisse réponcire aux besoins ae I'homme camusien, corriger le fau amour de la rérolive négative et servir de modèle pour une révolte unitaire. 3

Et si cette forme a'amour est idéale, c'est parce qu'elle "remplit surtout la condition de I'universalité, c'est-à-aire qu'elle peut résumer en elle seule les troiz Eomes a'anour de l'homme camusien: l'amour

3x Cuyer-Van-Huy, La Métaphysicue du Bonheur chez

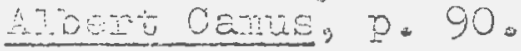


physique, I'arour 'humaniste' et l'amour métaphysique."4 Ia mère est non seulement l'éaucatrice de son enfant, nais elie est aussi celle qui participe à l'oeuvre de la création. Elle a mis un enfant au monàe et se sacrifiera jusqu'à la mort pour lui. C'est dans les yeux de sa mère que Rieux trouve le réconfort. Quant à rarrou, il se demande si la sérénité de Mme Rieux ne provient pas de cet anour universei. A son tour, IN Guyeriman-iny se demande: "C'est peut-être là I'idéa de la scinteté de rarrou et aussi de l'home ca-

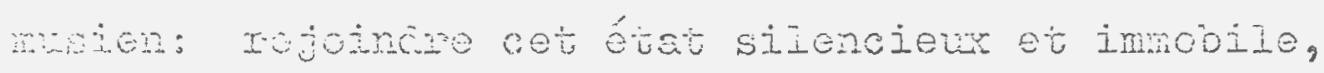

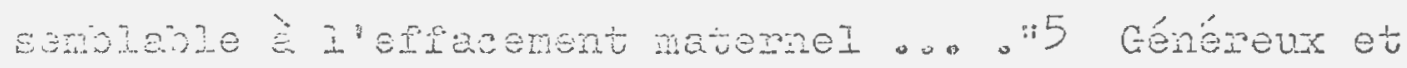
discreo, totalement aésintéressé, tel est I'amour que I'home trouve dans ie visage àe la mère. Celle-ci lui apprend à aimer et à donner sans compter. C'est encore Mme Rieux que Tarrou, agonisant, fixe avec intensité. II serble avoir trouvé en elle la paix qu'il avait toujours cherchée, la simplicité de sa propre mère, I'anoun universel et silencieux qui donne une image de I'étemité. C'est une véritable force spirituelle gui se dégage de la mère. Et pour comprendre toute se portée, il surfit de lire ces iignes de la prérace

$$
\begin{aligned}
& \text { 4Did., o. 89. } \\
& \text { 5Ibia., pp. 194-195. }
\end{aligned}
$$


pour ia réedition de I'Ervers et I'Enaroit:

Si... je ne parviens pas un jour à récrire

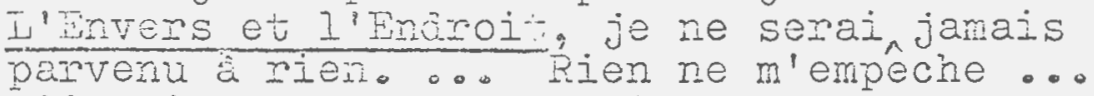
d'inaginer que je mettrai encore au centre de cette oeuvre I'admirable silence a'une mere.. Ce que j'ai voulu dire ici, c'est qu'elle ressemblera à IrEnvers et l'Endroit.... Je sais ... que c'est cela. Cela, c'est-à-dire cette vieille femme, une mère silencieuse, la pauvreté, la lumière ... I'amour solitaire et peuplé, tout ce gui témoigne, à mes propres yeux, de la vérité.6

\section{Ainsi, le lien qui unit mère et enfant repré-} wente le con de soi le plus total. Cet amour possède Is forje ul pert faire fi de la raladie et de Ia nort.

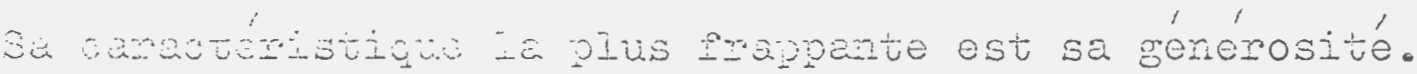

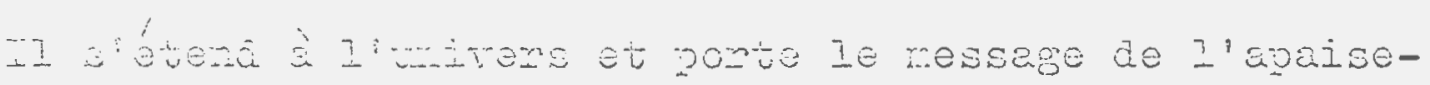
nente. Ia nère puise la rorce de son anour de la proPonde sagesse qui l'habite et inonde ceux qui l'entourent de sa tendresse bienfaisante. Son role est semblable à celui au sage ou du saint qui aispense la Iumière avec une sirnlicité et une bonté infinies.

Si l'amour maternel est porteur de paix, l'amitie pevit, au moins, être le chemin de cette paix. Tarrou a '́té souleversé en apprenant qu'aucun homme n'est indemne ae la peste. Il s'est senti coupable puisoue le mal esu inherent à chacun de nous. C'est pourtant l'amitié

Gibert Camus, Préface pour la rééaition de E'Divers et I'Enaroit, dans Essais, p. 13. 
qui Le délivre de son cingoisse. Une délivrance pertielle puisque ie mal est toujours lá; du moins a-t-il la possibilité ce puiser le courage de reprendre la Iutte contre la peste. C'est ce qu'illustre la baignade nocturne des deux amis. Le bonheur de sentir un etre Iraternel aonne le courage de continuer humblement à se pencher sur les maux des autres.

Tarrou avait un ami et c'est ce qui l'a aidé. CIanerce, le héros abanäonné de Ia Chute?, cherche un ani dar il sait que le seiut se trouve dans l'anitié. Ie mal est en nouj: contert en serons-rous délivrés si I'Anulgenze des autres re nous est das accoráe? VoiIà donc le cri de Clamence. Il se noircit devant ses complaisants interlocuteurs. Mais sa confession n'est qu'un appel ultime à l'Autre. Ce que Clamence vouarait, c'est que son interlocuteur, au lieu de l'accompagner cans sa chute, le retire de l'abime par un geste d'amour. Mais I'Autre ne comprend pas I'appel désespéré et Clamence ne peut être sauvé. De toute façon, Clanence sait qu'il ne pourra pas être sauvé car il est Iui-nême incapable a'amour. Ie salut viendra quand lui-mêne sera capable de "l'anitié parfaite" dont il parle. Pourtant, Clanence ne voudrait qu'un peu de ce 1956)。

$$
\text { 7Albert Camus, Ia Chute (Paris: Gallimard, }
$$


quiliprechait aurefois: l'anour du prochain au nom duquel il relevait ses ranches d'avocat avec autant de conviction. Eu pour que cetie anitié soit parpaite, iI Iaut qu'elle agisse avec pureté, non I'ancienne duplicité ae Cianence. I'aritié, si elle est aussi généreuse que l'arour maternel, peut être la chance qui mène au salut. Ceci semble être l'avis de Carina Gazourek pour qui Clamence," ... à sa facon, dit que I'nome a besoin d'indulgence, que le salut est dans

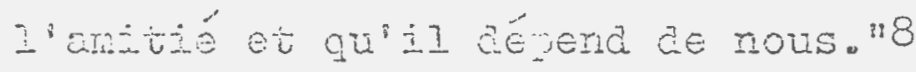
I'arow à conple serbie égalenent tendre vers un mirere qui se troure arwalè de le sensualité, à Ia ronterche de I'apaiserent de l'kine. Dans toute I'oevire de Cams, I'anow érotique ne semile jamais trouver satisfaction. Caligula aime sa soeur Drusilla uvec passion et il en est tendrement aimé. Ies prenières versions de cette pièce accoralent beaucoup plus a'importance à cet anour que la version finale. Dans ces versions, Caliglila s'exprime àvantage sur le lien qui le lie à Drusilla. Ieur relation a pu être appelée irceste. Mais cette relation vient souligner la soif d'absolu et de puretó qui anime Caligula. Pourquoi sa sovir ne pourait-elle paz être en même temps épouse? son áósir serjle tencoe vers l'union parraite. I'em- 
pereur romain veut retourner à la nature, celle qui a permis la vie de Drusilla et de Caligula. Ils étaient "ur." puisqu'ils provenaient de la même origine. Caligula veut perpétuer cette unité du ventre maternel. Quand Drusilla meurt, le jeune empereur voudra la "lune," elle-même symbole féminin, symbole de l'idéal impossible aux humains, mais qui représente la perfection. I'érotisre ce Caligula apparầt comme la tendance exirême vers un ancur pur et total. Qu'une soeur puisse être en même temos amante, voilà qui ajouterait une autre dinension á l'anour un peu égoíste du couple, le rendút ainsi plus géréreur.

Sone Marie demande à Meursault s'il l'aime, il zóna négativenent. Il refuse de dire aes paroles a'ancur puisqu':i ne ressentu que désir pour elle. reursaut consiàre le mariage comme peu important. Il préière ne pas se lier, se fixer d'une façon absolue. Le souvenir àe Camus lui-mêne vient à l'esprit. Camus n'a-t-il pas dit que le départ de sa femme Jeanne l'avait fait soufirir mais qu'il avait ressenti comme un soulagerent? Camus n'est pas rait pour la possession, Et Neursaut non plus. Ciest pour cette même raison qu'i présère être libre, libre de se donner à tous, du lieu de se liniter à la présence d'une seule peisonne. 
I'avour du cowpie se trouve encore dans les autres pièces ainsi que dars la peste. I'iaée qui scrole se äégager de cetre étude est que cet amour est insurfisart; ie couple ne doit pas se contenter de s'aimer; il lui faut se donner aux autres. Ainsi, dars Le Naienterau, Jan semble être pariaitement heureux avec sa femre. Cependant, il sacrifie son bonheur en faveur de quelque chose qui lui parẵt supérieur. L'appel qu'il entend et qui I'attire vers la maison naternelle semile avoir ure origine divine tant il est imésistivle. Jan a besoin de rejoindre la "demeure,"

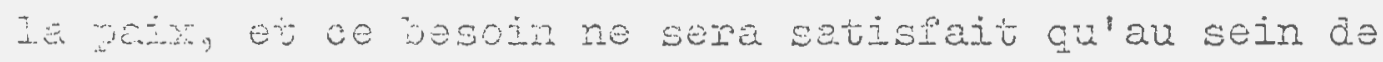

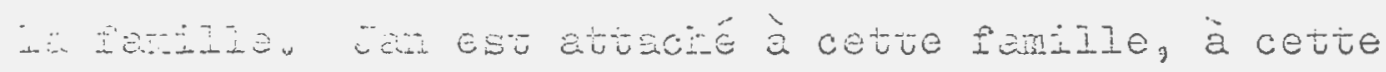

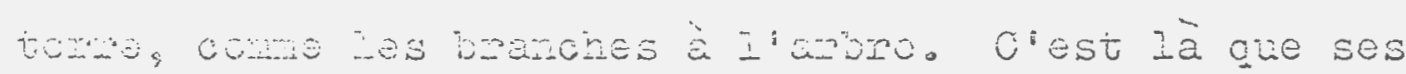
rajnes scrit iplantées, et s'il veut être heureux, il İus que les autres membres de la fanille le soient. Se dépouiller devient un geste nécessaire qui permettra à Jan de transcenäer son amour égoìste, atteignant Einsi l'anour universel. Pour atteindre ce niveau, Jar se áéguise. Il accepte a'être considéré comme un étrarge: pour "cevineı" Ies äésirs secrets de sa mère et de sa sceur. Il est venu apporter le bonheur, satisfaine les voeux inconscients, jouant ainsi le róle de Ia destinée, et payant de sa vie I'élan génëreux de son 
coevro

Que ce soit polis Eambert, Rieux, Jain ou Kaliayev, l'anour pour un seul indiviau doit passer au second plan en raveur d'un amour plus grand et plus généreux. Ces héros veulent se conner à l'humanité souritante, que celle-ci soit symbolisée par une ville assiégée par la peste ou menacée de tyrannie. Ieur but est de trouver la paix intérieure. Or, celle-ci est liée au bonheur du genre humain. Pour atteindre l'une, il leur faut oeuvrer pour l'autre. Ceci, ils le feront avec une foi éperaue, semblables en cela à ces missionaires á̂́roués jusqu'à la mort à la cause de Jésus Christ. Les héros camusiens ont donné Ieur Donfeur individuel polr se ávouer à construire I'arove univensen.

Dans "Ia Peme Aaultère," Camus introduit un nouvel élément dans son traitement de l'amour érotique. Il étuaie les nouveaux concepts de culpabilité qui accompagnent la satisfaction de l'amour physique, se rapprochent ainsi de l'ascétisme de Saint Augustin.9

\section{Gaint Augustin, imprégré de la conception} néopiatonique, croyaì̈ à la supériorité de lesprit sur la matière, I'esprit étant plus proche de "I'unité suprêre," qui trouvait sa fin en Dieu. Pour atteindre ce niveau spirituel qui représente la perfection, il lui fallátit se déraire d'une forte sensualité qui, de par 
Pountant, danz Ie cas de Janire, il s'agissait d'une vercontre jnefrable. Plle avait entendu l'appel de I'mivers auguel il est difficile de résister, surtout quand il pronet la cèlivrence, l'espace infini, la comminion avec le cosmos. I'ayant entendu, elle lui répona. Janine, la femme adultère, abancionne son mari au milieu de la nuit, pour épouser la nuit froide du aésert. Ce granā espace l'a arrachée à son horizon étriqué, et elie a acquiescé cevant cette violence. Ia description que donne Camus de la plénitude de ceute nuts est a ine beavié extrêne:

$$
\begin{aligned}
& \text { Acre, avec une doveen insupportable, l'eau } \\
& \text { de lo mut comence d'emplir uanine. sub- } \\
& \text { merges je frond, ronta peu a peu du centre } \\
& \text { cosem de son } \hat{e} \mathrm{u} e \text { et déboré en plots ininter- } \\
& \text { ropus unscia pa bouche pléne de génissements. } \\
& \text { I'instant à'apross, ie ciel entier s'étendait } \\
& \text { aumâssus a'elie, renversée sur la terre froide.10 }
\end{aligned}
$$

sa ratue, l'empêchait de s'élever au-dessus de la natière.

Camus a comnencé à s'intéresser à la pensée plotinienne alons qu'il écrivait son Diplôme d'Ptudes Superieures. II était venu à étudier la notion de l'amow selon Plotin. Cette notion représentait une synthèse des iáes de Platon, a'tiristote et de Plotin. Disons en substance qu'elie liait l'amour au Bien et au Pur. L'amour derenait une tendance vers le Bien Suprêre cu Un, en vue de l'unification dans l'infinité divine.

10 Gamus, "Ia perane Adulière," p. 34. 
Si la pencontre avec le aúsert est mystique, il n'en nesto pas moins qu'elle a été accompannée de toutes les renifestaticns physiques d'un adultère. C'est pour cela que Janine pleure à son retour. Eile a trompé son mari. Mème si son adultère a été le moment de la révélation, il demeure une cause de culpabilité. Janine a comminié avec ce qui n'était pas son mari. Elie a ressenti aians sa chair l'effet réäempteur de cette rencontre et eile adret la cripabiltté de la chair. c'est ce qui provoque son remords et ses larmes. In essayant de lutter contre las sens pour atteinare un niveau supérieur, celui de l'unité supaêne, Carnas rejoint la quête de jascète à recherche da Bien. Il conât toute la

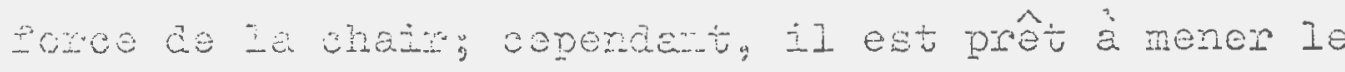

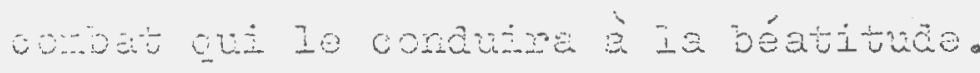
I'acpertence de Dor Jum 11, si elie z'oppose à calle de Janine par les moyens, reste touteiois la réne forme a'amour ascétique. Cela pourrait paraître paradozal. Il n'en est rien cer il ne faut pas oublier cue 1'ajsurde reste le point de aépart de Camus. Si Don Juan va de femme er fenme, d'amour. en amour, c'est pour pépondre au besoin urgent de I'unité: "I'horme 11Camus, Ie Mythe de Sisyphe. 
ajoure multopie encore ici ce qu'ii ne peut unifier."12 Or a parlé a'égoïsme àe sa part. Pourtant, y a-tu-iz d'emour pius généreux que celui qui se sait passager? Don Juar se jette chaque fois avec la même passion. Son attituce est d'autant plus généreuse qu'il se donne de tous côtés. Devant chaque femme, il répète le geste du saint; il se dépouilie de tout, se donne totalement, sans même croire à l'éternité de son amour. Ce geste est un véritable exercice d'abstinence puisque Don Juan se refuse à être avec une seule personne car

Ceux cu'un gand anour détoume de toute vie personnelie .. apaurrissent à coup sûr ceux que lewr,amour a choisi. Une mère, une feme passionece, crit nécessairement ie coeur see, ba: 1 est a btoume du monde. Un seuI sentiment, un seu? $\hat{\theta} t r e, u r$ seul visage, mais tout Est devore. 13

Jor Tuar se wait hortel et c'est la forme d'amour qu'il a choisie qui le libère de la hantise de la mort.

Cette forme a été étiquetée sous le terme de jouissance, se trouvant ainsi áénuée de toute valeur morale. Pourtant, ainsi que l'écrit Quillot, la tentative de Don Juan n'est que "... Ia passion de soustraire al temps une parcelle d'éternité par la frénésie sersueile comme par le renorcement ascétique." 14

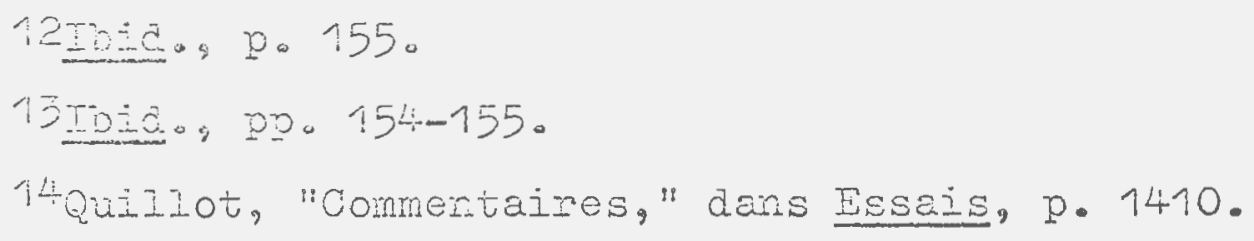




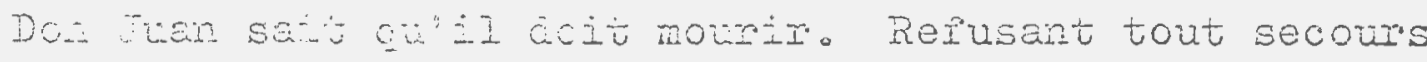
ditin, iz afronte la mort et lui arrache wi moment a'éternzté en la dépassant. Sa quête devient alors une currse eferéné pour atzeirare le sort bienheureux de êw qui on't trouvé leur place auprès de Dieu, partageanu avec Iui la vie éterreile.

I'absurée qui rỏge dans le monde atteint son paroxysme en présence de la mort. Cepenciant, Camus ne se Ijisse pas abattre. A I'irrationel de la mort, II oppose le lien incestrubiole et récempteur qui

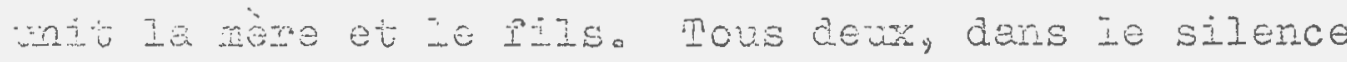

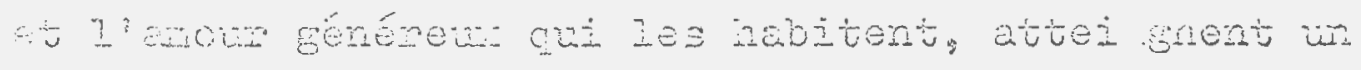

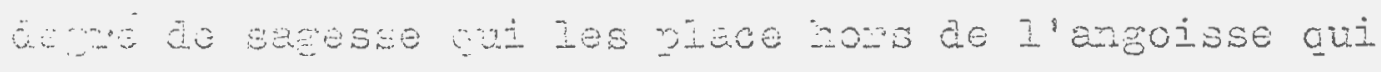
nav de ia nowt. A wh ceró roindre mais toujours senesateur a'érergí, I'anizié est la source du salut. Elle insurple ia vie et le couraje aux combattants de Ie peste, Leut donnent ainsi ces ames contre la mort. I'anour érotique tend vers le même but purisicateur. II reut ópasser son horizon égoiste pour atteinare une pius large envergure, embrasser l'univers soufnont dans wne nête étreinte genéreuse. Se voulant parfait, cot amour cherchore è vorouver l'urité supene, soit par le jouisanice sensuelle, soit par

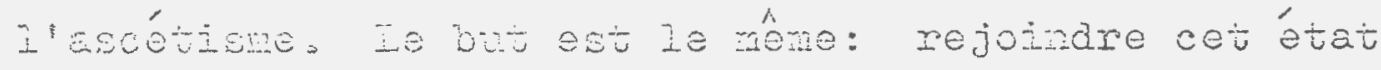
de peju et ce réconciliation avec i'univers, état 
uri rapelle Étrangenent la communion du saint avec I'esprit divin. 


\section{CHAPITRE VI}

\section{I'INNOOENCE}

Pour que l'on puisse parler de sainteté, dans un contexte chrétien ou non, il faut partir au concept cie l'innocence. Ne peut prétenare à la sainteté celui cui se sent coupabie. Or, jusqu'à Ia Peste, Camus avait mis I'accent sur I'innocence de I'homme, accusant les forres extérieures à I'homme du mal qui règne ders I'univers. Aveo Ia Chute et I'auto-accusation de oiarence, Ie poblème devient tout autre. Come I'écrit Sinch, "il ne s'agit dono pius de la róvolte du bel tonccent contre l'impureté de Ia conscience sociale, mais à I'angoisse nétaphysique ae l'être qui a découvert son intime cuipabilité."1 Canus ne croit plus à I'innocence totale àe l'homme. Celui-ci a une grande part de responsabilité dans le mal. Cette prise de position a suscité un véritable bouleversement. Ies critiques, déroutés par ce retour soudain vers le soi, se sont lancés dans les spéculations les plus aiverses. Pour certains, Ia Chute est "... la sourde satire

isincin, Présence de Camus, p. 170. 
Q'une centaine épicénie ce notre temps: la maladie du scrupuie, l'obsession de la culpabilité, qui attaque non seuiement l'équilibre moral de la personne, mais la santé du corps social et jusqu'aux valeurs de la civiIisation."2 Pour a'autres, ce récit avait pour but de démolir l'image trop rlatteuse que le public avait de Carus. I'auteur de Ia Chute voulait exorciser ses défauts en se coniessant. Thomas Hanna semble être de cet avis: "Ue finc a portrait of the Canus we know, indeed e enf-portrit as astonishing as it is admirable in its seif-deprecating honesty. ... It is simply a confession."i cette demière interprétation a recu l'apzrovation de tous cewx qui pensaient que camus était sur le point de se convertir au catholicisme. Ie fait est que Ia Chute est une préoccupation Q'ordre cirśtien. Ceci est rendu évident par les nombreux symboles chrétiens qui se retrouvent tout au long du récit. Ie monologue de Jean-Baptiste Clamence, monologue qui semble appeler du fond du désert une réponse à sa quête, fait penser à la tentative de purificauion du saint chrétien. Clamence semble vouloir se débarrasser ce tous ses vices par la confession, agis-

\section{ISid., p. 174.}

Banna, The Thought and Art of Albert Camus, p. 167. 
sart ausi conne le perait ur chmétien. D'une façon śrémale: vlanerce apvanaît come un assoiffé de pureté ct d'imccence, et son récit retrace les affres ae itindiviu aux prises avec sa conscience.

Qu'esu-ce qui a provoqué la chute de Clamence? I'orifine du rire qui a brutalement éclaté dans son dos un cervain soir est ce qui lui a donné ses premiers doutes. Sa provenance reste mystérieuse. Clamence ne croit pas aux anges; il ne croit pas non plus aux sortilèges de la nuit. Alors, cette voix ne peut être que celie àe sa conscience. Le caractère de ce rire révèle Le geme de préoccupation qui habite Clamence. II

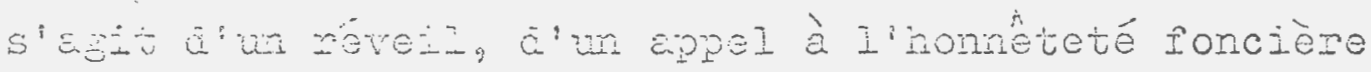

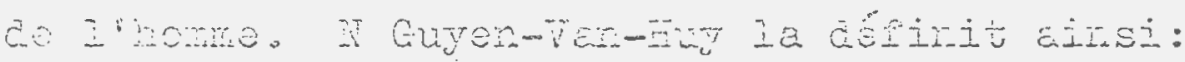
"Cotue voin ... ne peut btre celle du ral, mais celle au bien; elle ne peut être celle àe la haine, mais celle de I'amour."4 Anirant l'esprit vers la pureté totale de l'acte, elle représente la conscience morale de l'home à son ciegré le plus élevé.

Le titre du récit, ae par sa connotation biblique, a suscité beaucoup de questions quant à la sigrisication de cette chute. Faut-il prendre la chute dans Is sens religieux et se réiérer au péché originel?

4r Guyen-Van-Euy, La Métaphysicue du Bonheur chez Aloent camus, p. 218. 
İ y e quelaues éléments cans le texte de Camus qui autoriseraient une telle interprétation. Clamence afPime avec désespoir que persone n'est innocent. Noüs sommes tous coupabies, même celui qui symbolise I'innocence, Ie Christ Iui-même: "La vraie raison est qu'il savait, Iui, qu'il n'était pas tout à sait innocent. Sill ne portait pas le poids de la faute dont on liaceusait, il en avait commis d'autres, quand mêno, il ignorait lesquelles."5 II ne suffit d'être iirectement responsable pour être coupable. Ia faute revorte plus raut, Si mêne le christ ne peut prétenảe ¿ I'inoconse totale, comment pouvons-nous la réclamer? Il exisue us autre élérent qui fait ásespérer

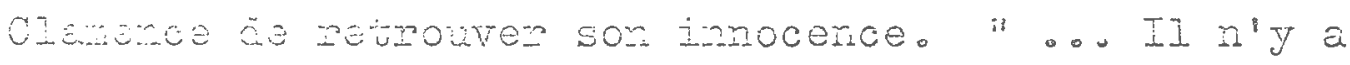
plus a'agneau, ni d'innocence ... "W affirme Clamence. Ie ronde abrrire les faux juges, sans se rendre compte que la véritié est enfermée. Les hommes sont réduits à adorer un vernis, aveugies qu'ils sont devenus par leur fausseté. Ies esprits sont tellement voilés qu'il ne leur est olus possible de reconnaitre les vrais juges, le vénitable agneau. Les seuls juges capables de dis-

$$
\begin{aligned}
& \text { Eamus, La chute, p. } 130 . \\
& \text { 6Ibia., p. 151. }
\end{aligned}
$$


penser ur jugumert intègre ont été retirés. Avec eux s'ci va l'espoir du pardon et ae I'irdulgence, car les faur juges re savent que conämner: "Et moj, je plains sans asoudre, je comprends sans pardonner ... ."7 Avec ew disparazt également l'espoir de retrouver l'agneau innocent, celui qui "... couchera sur le sol pour novis. 18

Ies flocons de neige que forment les blanches colombes restent suspendus dans le ciel d'Amsteräam. Encore win signe du ciel qui parle aux hormes de leur ircìizizé:

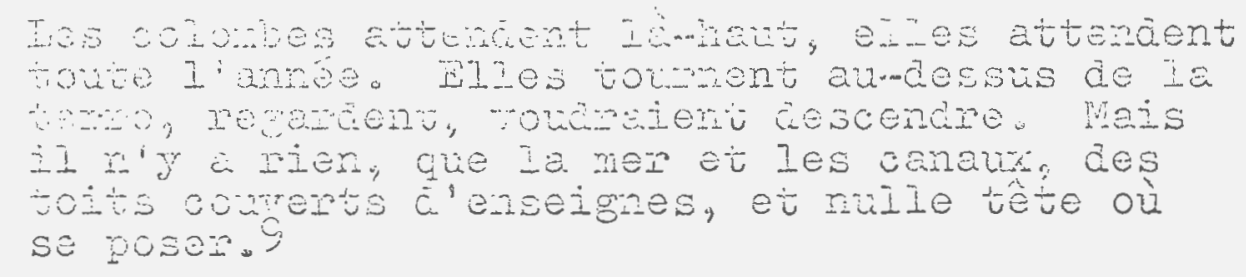

ivile tête n'est plus àigne au contact céleste et rêanpteur. Mais là où la conciamnation se fait la plus rerquée, c'est quanà Clamence laisse échapper son impuissance à changer:

Wais quand on n'aime pas sa vie, quand on sait qu'il iaut en changen, on n'a pas le choix, 'est-ce pas? Que faire pour čtre un autre? Inpossible.10

$$
\begin{aligned}
& 7 \text { IOEd。, p. 165. } \\
& \text { 8ISE⿰ D. } 40 . \\
& \text { 910ia. pD.86-87. } \\
& \text { 10Ioidog. } 157 \text {. }
\end{aligned}
$$


Yu plis loin, il ajoute: "Il est trop tard, maintenavi: il sera toujours trop tard.:11 condamés par la faute du premier horme, ses descendants devront porter Ie poids au châtiment. Le péché originel ne peut pas ètre eriacé.

Pour accepter une telle interprétation, il faudrait que Canus admette I'existence de Dieu. Or, nous savons que Dieu est absent de son univers. Que devient zlons le seis de la cinte si elle n'est plis une préoccuparion du promier péché? Selon Thonas Hanna, la chos de Glomence n'est pes celle qui wane de l"innococe la culpabiitú, nais de l'inconscience à la

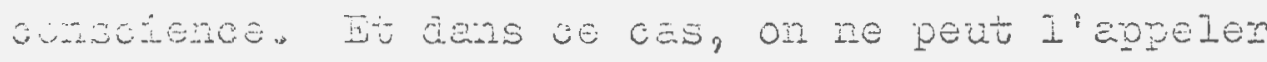
cisite:

Ee was no longer sare or unconscious; he was in trouble. His virtue colida not justify his action; he alone had to be its justification. Fron tisis point onward, Clamence moved toward consciousness and the agony or decision. In this respect Clanence did not rail downward but uprard; he fell into a higher state: that of self-conscious freedom. All things told, he is rorally more solia than he was previously. 12 I- ne $s^{5}$ agit done pas de la perte du premier jardin et de la première innocence car Clanence ne voudrait pas ce se vertu passéo. Ce cont il a pris conscience est $11=0.00 \%$ p. 170 ○. 170.

T2Hama, the Thought enc Art of Albert Camus, 
que son innocence passée n'était qu'ure iliusion. De 3 s "chte $_{\text {" }}$ il a retiré une prise de conscience aigue de la véritable nature de l'home. Il a aporis avec zngoisse que l'homme est césespérément libre d'aller vers le bien, ou vers le mal, c'est-à-aire quiil est abandonné et que rien ne peut garantir son innocence. Ia seule fonction de Dieu et qui est de pardonner et de garantir l'imocence de l'home, ne peut être appelée à I'aide puisque Dieu est rejeté de cet univers。

Néanmoins, le caractère de cette chute prend de oins ex plus wn zens chótien si l'or considère I'état

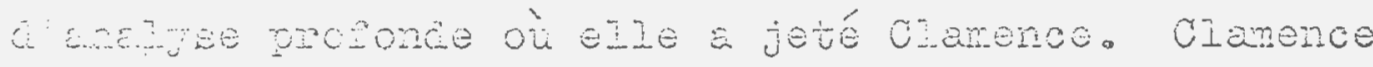

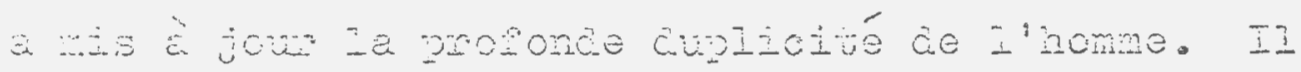

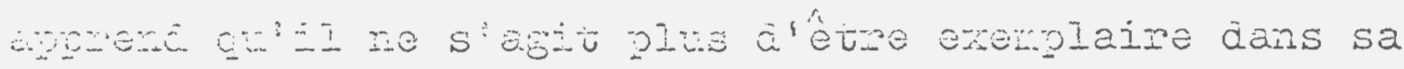
vie quotiatene. Làn'est pas le problème. Se retipant en lui-mêne, il constate le jeu ce l'individu ervers le toi le plus inime, ei il aévoile l'hypocrisie de l'home envers lui-mẻme. Clamence avait dédié sa vie à "Ia veuve et à I'orphelin." II était admirable a' abrégation et de cénérosité. Sans être chrétien, il suivait les poincipes premiers du christianisme: I airait son prochain, était géréreux de nature, faisait le bien chaque fois quil en avait I'occasion. Nais Ciamence n'est pas satisiait. Il a appris qu'il ne 
sufizait pas de faire le bier pour se croire innocent, indeme de la peste. Il a découvert que son désir de fáire le bien n'était pas ronnête:

Moujours est-il qu'après ae Iongues études sur noi-nểre, j'ai mì au jour la duplicité proronde de la creature. Jiai compris alors, à lorce de foullex dans na mémoire, que la nodestie miaidait a biller, I'hunilité à vaincre et la vertu à opprimer.13

S'il ne suffit pas de faire le bien pour se croire inrocent, que aeste-t-il à faire? I'attitude de Clamence était vourtant celle du pariatt chrétien. Si cela est wet, alons: Ia duplicite de cienerce est arssi celie cu orétien. Il faut alier de I'avant chercher à sarotr les robiles de la vertio Ia vertu gratuite ne sembie pas exister. Ou elle est au service de la saiisfaction personnelie, ou elie vise encore plus haut: la récompense du ciel, une place au paradis.

Ia réponse de clamence est celle du véritable chrétien: il bat sa coulpe, s'accusant de sa auplicité, et demandant l'absolution pour ses péchés. Mais là ò le chrétier se repent en sounettant sa volonté à celle be Dieu, I'auto-accusation et I'humilité de Ciamence l'ejaent à troner. Une fois de plus, la duplicité est mestresse: son repentir n'est que le servant de son arguil. Il s'accuse d'être bas et invite les autres

Э3anus, Ie Chute, p.99. 
Ésuilier. Cependant, au liev de se paintenir dans cetve numilité, il en tire gloife, se mesurant avec Dien.

I'orgueil est la préoccupation qui est à la Dase du christianisme. Saúar, le premier orgueilleux, est considéré comme celui qui a osé se mesurer avec le Dieu Suprêne, dériant ainsi la toute-puissance du créatew. A la source de I'orgueil, se trouve I'amour démesué que rolis nous portons et qui provoque tous les 世ave:

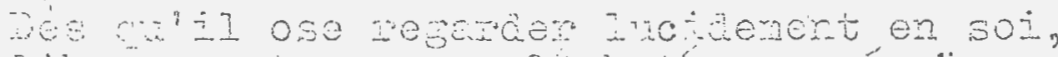

$$
\begin{aligned}
& \text { z'Len y trcure se labete, sor écoisme, et ses } \\
& \text { vorus lut apperaisent comrompues paw } I^{\prime} \text { a- }
\end{aligned}
$$

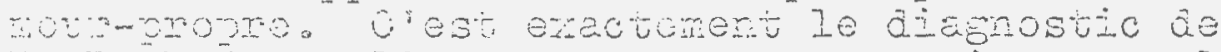

$$
\begin{aligned}
& \text { He Rochotoucula, an acoord sur de point avec le }
\end{aligned}
$$

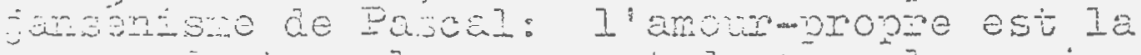

$$
\begin{aligned}
& \text { source de tous les maur et de tous les crimes, } \\
& \text { et il corrompt toutes les vertus.14 }
\end{aligned}
$$

De I'ange parfait, I'amour-propre avait fait un ange déchu. Ie crame àe Clamence est qu'il voudrait atteināre l'humilité totale, l'humilité du saint soumis à la volonté divine. Mais comment y parvenir? Ia religsion chrétienne diu qu'il saut ainer Dieu, et qu'airer SE création revient à I'aimer. C'était l'attitude premièro de Clanence qui se donnait à son prochain. Ià encore, pourtant, il a appris que son amour des homes n'était que mépris pour eux. Instalié sur les

$$
{ }^{14} \text { Simon, présence de Camus, p. } 171 .
$$


cimes de ie satispaction, il daignait aispenser sa bienveizlance aux autres mortelse Ia source du mal de olemence était son orgueil effréné, l'obstacle principai qui l'empéchait d'atteincre I'innocerce.

I'ongueil de Clamence était la cause de sa bienveiliance. Cet orgueil était au service de clamence Iui-nême. Il lui procurait une satisfaction personnelle âs plus grandes. Mais Clamence n'est pas le seul. Il existe un eutre personnage qui a vendu son âme pour atteindre les cimes de I'amour-propre satisfait. Ainsi s'exprime le renégat: "J'allais au-aevant aes jenjences, je rognais sur l'oucinaire, enfin je voulais bue w exaple; noi anssi, pour ciu ne voie, et qu'en

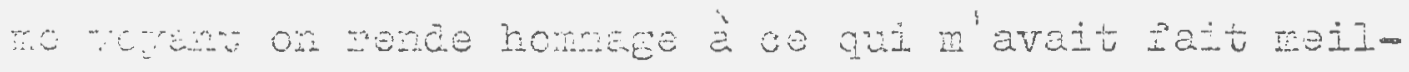
Lex: à travers noi saluez mon seigneur.115 ce cue Cazus cénonce ici est un des points les plus importants Qu cristianisne. I'orgueiI de Clamence avait pour but de lui faire croire qu'il était parfait. Celui du Renégat a pous but de lui faire croire qu'il est Dieu. Grâce à ses mortipications, il s'abaisse au niveau le pIrs bas d'où il se reièvera pour narguer Dieu lui-même. Ainsi, nous re pcivons mêne pas être assurés de l'innoserce au plus hunole des saints.

15 Aldert Camus: "Le Renégat ou un esprit confus," axis Itsizet le Royaume, p. 40 . 
C'est seulement dans le contexte Juâéo-Crrétien que I'on trouve une telie importance accordée au concept de l'orgueil dans le saiut de l'homme. Dans ce contexte où Dieu est censé être le commencement et la iin, la vie et la mort et dont la volonté est révélée, il est essentiel que tout ce qui fait partie de la création se sounette à cette voiorté suprême. Prêcher I'hurilitié devient alors une règle de base que tout crivétien se doitu de suiveo wais queile est l'inporvace de I'hmilite dens un univers dü Dieu est absan,? Ihome camusien ne ae scumet à aveune volonté suórieune yaree qu'il no pecomât l'existence d'aucuns. Gependant, aans son ceuvre littéraire come aans sa vie privée, Camus n'a jamais cessé de lutier poun auteindre le Bien Supréme, Bien très sembiable à celui cui est prêché par les chrétiens. Nous connaissons le point de départ de Camus: I'absurde règne dans I'univers. Ceci établi, les notions de bien et de mal perdent leur valeur puisqu'elies n'ont aucun sens dans un monde ebsurce. Dans un tel monảe, ia poursuite a'un idéal oasé sur I'ancum des homes, I'humilité, la charité, En vout se cue prêchait Ie Christ, devient gratuite. Cetve rechezche n'étant basée sur aucun principe siEnificotif, elie ne peut avoir pour but que la satisfaction pezonolie de celui qui ia pratique. Arrivé 
à ce point. I'homme cemusien atteint I'impasse de clamence, "... ce point culminant oì la vertu ne se roumpt plus que d'elie-mêne.:16 Jusque-là, la tentative de Camus avait été une lutte pour se purifier de tous les vices qui encombrent l'homme, et atteinare I'imocence parieite. II a regará sans faiblesses ses moindres feutes, et a essayé d'en venir à bout à force de zucidité et a'honnêteté. Mais cette lutte névait cirigée au service de persome si ce n'est à L'Aéai d'home, I'home paraiterent vertueur, I Lune cont i'innocence est garantie. Ia gratuité

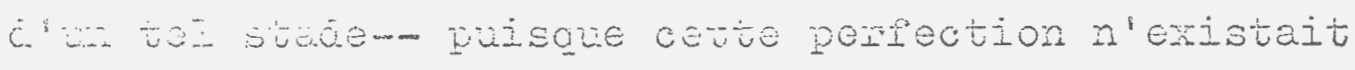

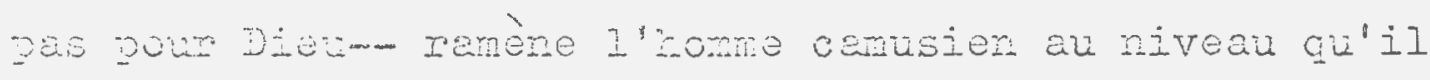
avait voliu fuir: I'orgueil de la perrection, des somets; la satisfaction de soi. La lutte de Camus pour l'innocence semble devenir un cercle vicieux. Son âme aspire à la pureté. Mettant tout en oeuvre pour l'atteinare, il arrive à un niveau proche de celui quil convoite, simplenent pour retomber dars le pasmien orgueiz.

Ever Ie Crute, Camus à poussé la réflexion noxuie à un nivea jamais atteint auparavart. Sa préoccupation a'une âne entièrement dénuée de fausseté est proche de ia recherche du parfait chrétien qui veut

i6anus, Ia Cinte, p. 30. 
mejoinire son créateur. Nettant à jour les multiples nobiles cachés de la augicité humaine, il atteint un degré rarenent atteint àe luciaité et a'intégrité morale. II ne suffit pas a'être en accora avec ie monde, nous dit-il. Cela ne représente que le premier pas nécessaire qui doit conduire à la lutte plus arciue contre I'orgueil humair. En mettent l'accent sur les principes de base du christianisme, Camus révèle une démerche perallèle à celle du saint chrétien. Si le but utire n'est pas le mêre, la démarche reste identique.

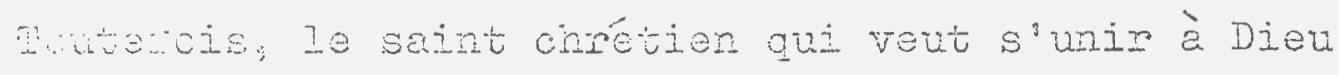

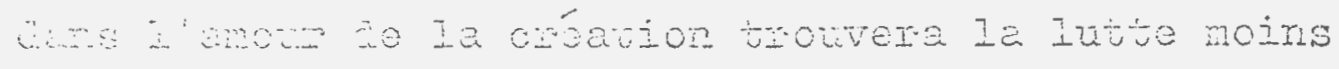

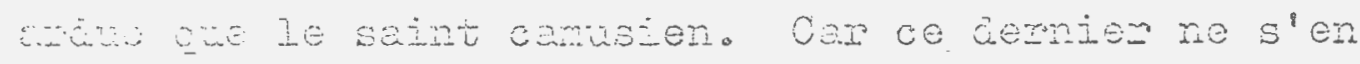
remer b̀ personne pour ie guicier. Ii agit pour le Bien sans iui reconiâtre de sens, mais surtout, c'est Iibrement qu'il a choisi cette route. Abandonné à lui-mêre, il aspire touterois à la pureté, source de saiut pour le saint chrétien. 


\section{CONCIUSION}

Come pour Tamrou, c'est en face de la nort que Carus a pris conscience de I'absurde qui rème dans Ie monde. Ce noment représente la prise de conscience devant le mal et constitle le début de ce qui va être la croissance spirituelle du jeune Camus. Après s'être débattu dans I'amertume et la folie cusctées per cette oruscue connaissance, Camus a

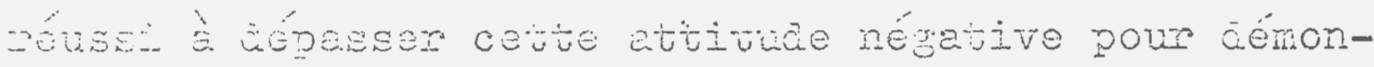
urer quil existe des valuus qui nèritent d'être déHendus. II a pris conecience de I'absurce et a voulu le ápuser, transender tout de qui avilit I'homie. je premier mouvenent de sa croissance spirituelle a été d'englober l'hurnanité dans sa révolte contre un univers de larmes: "Je me révolte, donc nous sommes." Cette arfirmation de Camus étend aussitôt un lien mystique entre tous les hommes opprinés par un Dieu vengeur ou par le hasara, par la néchanceté a'autres hommes ou par la mauvaise chance, on, d'une pacon généralo, par le maj. Mal extriteur à l'hompe, mais aussi intérievr. Il s'agit à s'unir spirituezlenent et de se aresser contre 
ce qui cmpêse l'home de s'élever, en le gardant prisoniez de la port et du mal. Mais il raut égalewent dire non è la facilité en combattant le mal. En dénorgent lo mal, il paut se garder d'utiliser ses ames, à savoir I'arbitraire et I'injuste. Apôtre de la pureté des moyens, Camus prêche ure ligne de conduite difficile à suive parce qu'elle ne tient pas compte des ásauts qui constituent le caractère humain. Il chost l'aspiration que chacun de nous sent vers Is putué trtale et concentro ses erorts dans cette

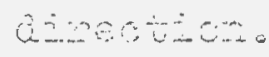

Le scildarité envers ies hommes, quand elle est pure, a lin pouvoir salutaire. Cette soliaarité se lait sans considération de politique ou de religion. I'home se sent un élan fratemel quand il voit un autre homme dans la souffrance, et cela ne vrovient pas du fait qu'il croit agir au nom de l'amoun divin. Ce n'est pas au nom de Dieu que I'home aide son prochain. Et pouriant, le sentiment religieux se retrouve dans ce qui enime I'home camusien. Son anour ces honnes se veut distinct de l'anour de Dieu, wis $i 1$ est enpreint de tout ce qui anime l'amour chrétien. I- possèa I'élan généreux et irrépléchi ae touté la persone vers autrui, come l'élan de 
a'Amest vers un riere reurtri par une pierre; il oossède encore la générosité répiéchie de Rieux qui sacririe héroúquement le seul bonheur terrestre possibie pour salver les corps ravagés par la maladie. Ia Pratemité aes homes est un lien naturel et I'homme s'y aone en toute simplicité.

I'amour que Dieu porte à ses créatures est un amour régénérateur. Il les a créées et il veut, ¿̀ tout rroment, les aider de Sa Sagesse et de Son Amour. C'est par cet amour cui donne l'absolution

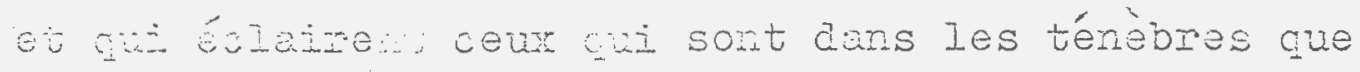
Cande wo attiá. Un appel motérieux et mystique

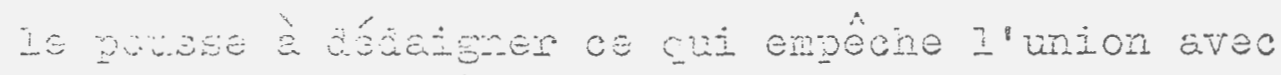

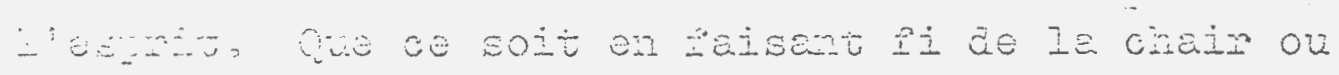
en s'y adonnart, Camis est en train ce tendre vers I'min spirituelle. Il montre we tendance er faveur de l'ascétisme à saint Augustin, mais il reconnà̀t également que la recherche de Don Juan n'est pas éloignée de cet ascétisne. Don Juan proclame qu'il aut aimer de toutes ses forces, épuiser toutes les chaces d'amour, pour saisir, ne serait-ce qu'un instent, an monent d'éternité. Cela semole également êre le sounait de tous ceux qui veulent aimer Dieu, atreincre I'uiton spirituelle dans I'eribrassement 
aivin.

Réclamant ine justice parfaite comme les dieux éguptiens réclamaient un équilibre pariait de lem balance ce la justice, Camus aspire à établir une justice divine, mais qui serait établie par des hommes. Pour cela, il faudrait que le juge soit aussi pur que I'agneau nouveau-né. Pur, et certain qu'il $r^{\prime}$ à rien à se reprocher, et qu'il lui est donc permis de porter ur jugenent sur quelqu'un d'autre. Cela revient è àre que le juge doit avoir les vertus de Dieu Inimêne car qui, en aenors de Dieu, peut se yonten de ravoin janeis péchó? Camis, tout er reLus ies onsolatios d'u Diev, présente une

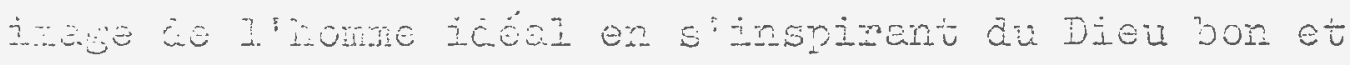

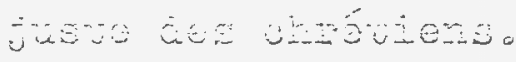

Uunde derance que ie juge soit innocent s'il yeut Etre un juge parfait. Mais l'Agneau mystique est enfermé, et le symbole ca cette perte a été brandi par Clanence. Plus d'innocence libre, plus a'espoir de voir quelqu'un se sacrifier pour nous et Iaver nos péchós par sa pureté. rl ne reste plus que Ies iaux juges, les jugements hypocrites qui perdent tout ien sens àécuité et àintégrité. Comment

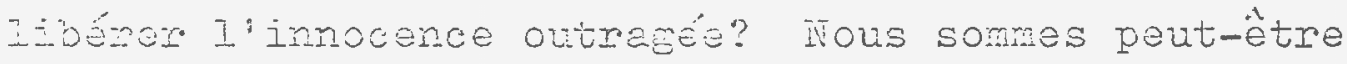


conamás par une malédition. Il ne peut s'agir de colle qui poursuit la race de Cáin puisque Canus ne reconnat pas le Dieu de celui-ci. Tout ce que I'on peut dire, c'est que Camus aspire de toute son âme à la vie simple et parfaite äu Christ. Pernande Bartield s'exprine ainsi à ce sujet:

Ces aspirations? Il semble que Camus ait souhaito atteinare et pour ainsi cire réaliser ce type icéal a'homre qui lui était apparu dans le Christ. Nostalgie d'une resserblance? Goút secret d'une nouvelle Imitation du Christ?1

Si Camus veut suivre les vertus du Christ? Ce qui est sim: e'est oue la vie du Christ présentait beauochp d'attreit pour Camus. Il voulait un monde par-

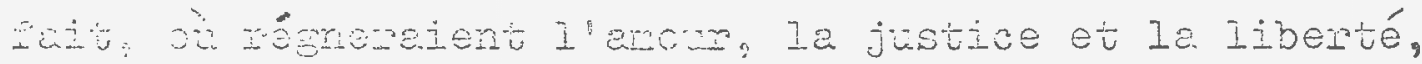
le bonkeur ot le vie. Leisacas la parole à Camus ivinene:

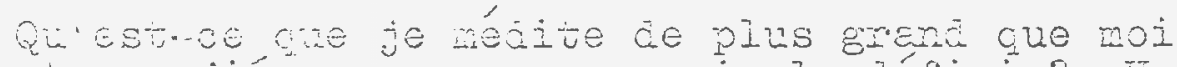
et yü ¿́ppoute sans powoir le définir? Une sorte de marche difícile vers une sainteté de la régation-... un héroísre sans Dieu-- l'homme pur enfin. Moutes les vertus hunaines y compris la solitude a' ígard de Dieu.2

Jaté cans un univers réglé par le mal et la scupfrance, et où I'home lui-nême prête au mal,

Tremende Bartfelc, "Camus et le Mythe du

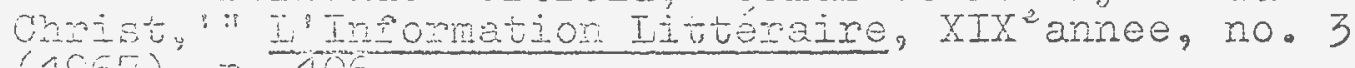
$(1957)$; 0.105.

2Cann: Gemets: Janvier 1942-mans 1951, p. 31. 


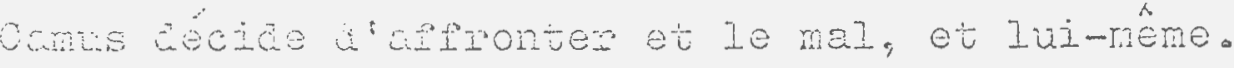
Ceci, í Ie fait en prônant une religion lä́que, entièrenent touriée vers I homne, tout en se serm vant des principes chrétiens, et en suivant leur example le plus aigne, le Christ Iui-méne, martyr de son anour pour les hommes. Nous comprenons à présent à quò aspirait Tarrou, et comment sa sainteté pouvait se passer de Dieu. Otto Friedrich Bollnow a donné wre Aéfinition de la sainteté de Camus: "Un saint sans Dieu,' cena veut aire se donner au Bien sans liniwes, recomengant toujours, par ce moyen, I'oeuve

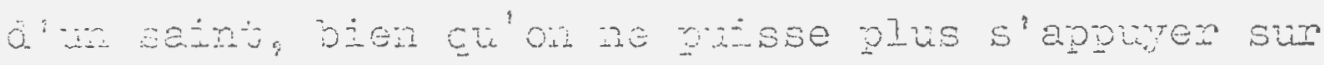
IE grofea eves, Dien ou'il failie craindre eu corm Unaire, cue tout re demeure en fin de compte parfaitepent vain, et qu'on ne puisse fournir a'efforts Qui n'ajlinent se perdre àns un espace vide et àbsurde."3 Cette sinteté qui re se réclame pas de Dieu est d'autart plus amirable qu'elle n'est basée sur aucur privilège certain. Le saint chrétien aine Dieu. Il sait que Dieu est anour. Pour rejoindre Dieu, il iui sufit ae choisir l'anour et le bien.

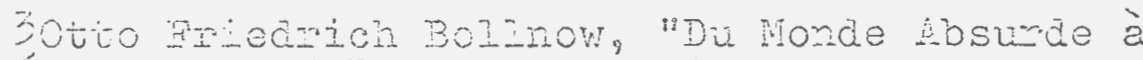

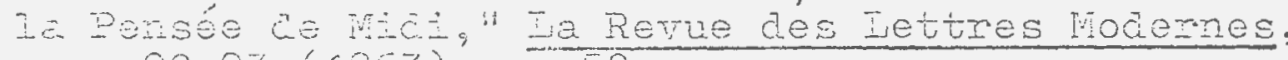
r.on.90-93 (1963), p. 50 . 
Canus ne pread yas le mére départ. Four Iui, Dieu nexisto pas. Pourtent, il pait le nêne choix que le saint chrótien: il choisit le bien, acte purement gratuit-- mais admirable-- puisque rien ne devrait le $-0 n c e=$ à choisir la rolite airfícile, le monde et les vaieurs de oien et de mai étant absurdes.

Eomme du $\mathrm{XX}^{2}$ stècle, héritier de deux guerres, Camus représente I'homre assoirfé de la pureté origirelie. Ioin des machines meurtrières, loin du netértalisne noderne, il désire établir l'homme parfait. Cet home serait meilleur oue I'home mocierne car il appencrat à être aussi pur et aussi innocent que le rinst. Oez hone sereit ejalenent désirewr

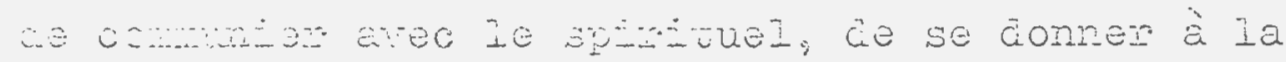

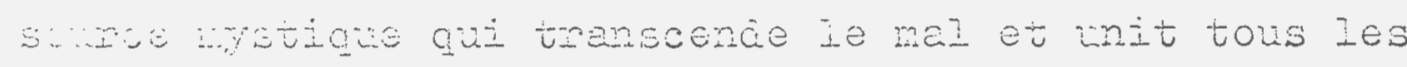
honnes ans un anolin ocmun. Nentation de la sainteté? oui, car du iond des ténèdres gui re reconnaissert aucur Dieu, Camus a su choisir une marche gratuite qui ccinciàe étrangerent avec celie du saint. N'attendant de sa recherche que ia paix de I'äne, son mérite est d'autant pirós élevé qu'il re croit rêmo oas à une jusüication ultine â son action. Ia quête de Camus vers un disolu qui áécasse les limites munaines est l'üz: qu'entendent ceux qui veuiert se consacrer à 
Dieu, aur homes, au soulagement de la misere. C'est aussi l'aspiration des êmes pures, ou qui désirent désespérément I'être; c'est enfin la préoccupation hautement consciente et iuciàe a'une morale du bien intransigeante. En se aonnant à ce qu'il avait àe plus pur en lui, Camus n'a-t-il pas choisi le seul chenin possibje pour un home conscient du XX"siècle? Dieu est mort, nous àsent certains. Abandonné à lui-même, plein d'engoisse, vers qui, vers quoi, se tourmera inowe de Ir désilinston? Carus semble avoir choisi

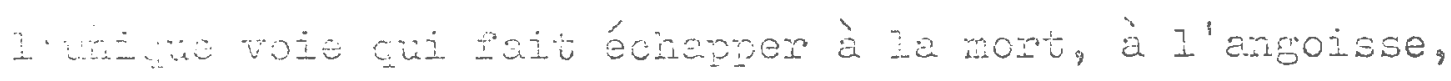

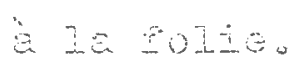




\section{A. OEUVEES DE CANIUS}

"Aotuelies I: Chroniaues 1944-1940." Essajs. Eajté

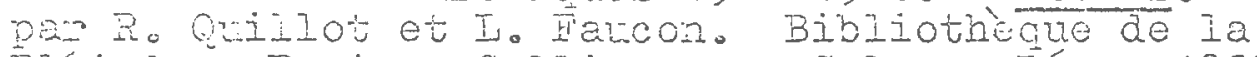
Pí́cade。 Paris: Gallimaró et Calmann-Iévy, 1965.

"Rotrezles II: Chroniques 19,4-1953." Essajs. Eatté pew . Quiliot ot I, Fiucon. Bibliothèque de la

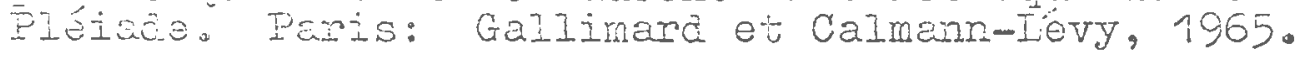

C.jer Ire Iivre de Poche no. 1491. Paris:

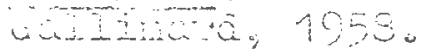

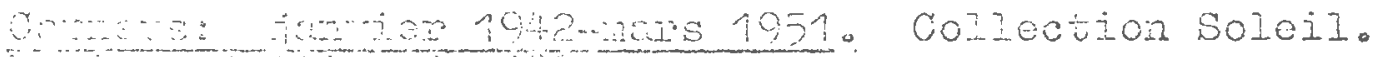
He:

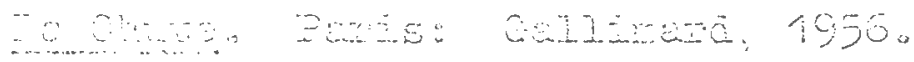

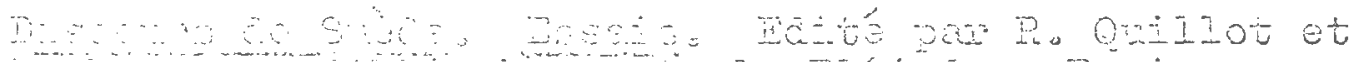
and

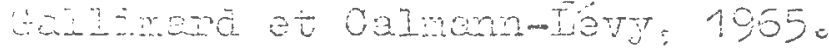

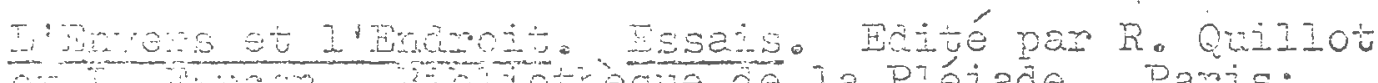
ev

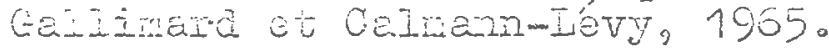

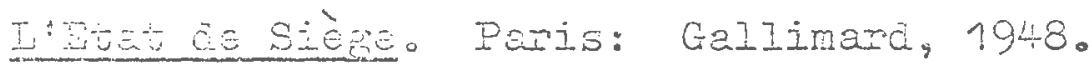

Husanen, Paris: Galizmard, 1942。

Lit I et IE Fcyeume Le Iivie de Poche ro. 1679.

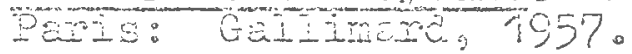

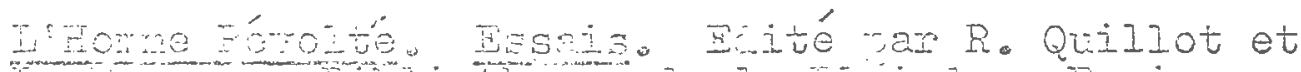

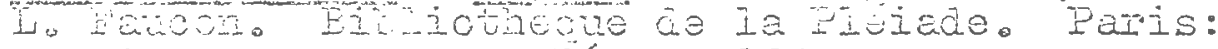

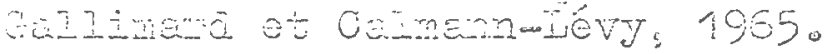

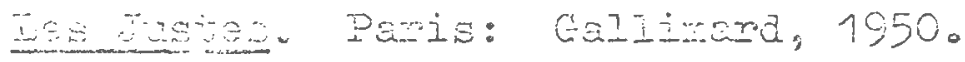




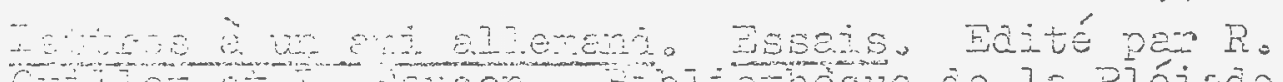

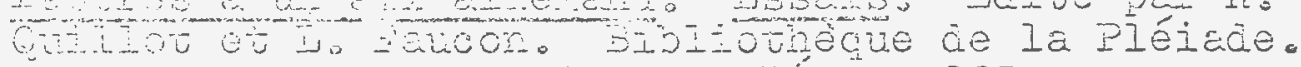
Fons: Gelizman et Caimenn-tevg, 1965.

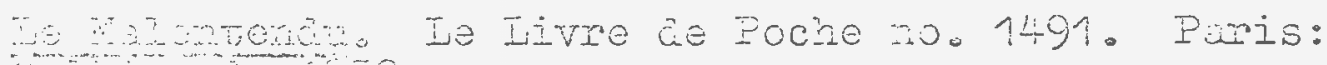

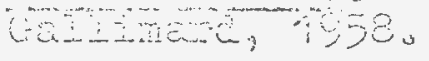

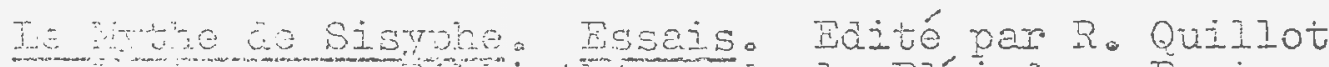

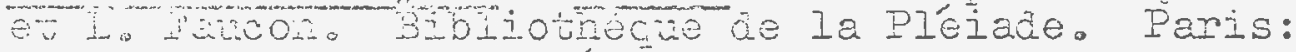

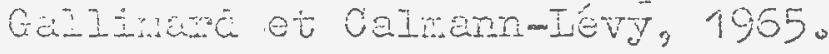

Le Pesta Le Livie de Poche no. 132. Paris:

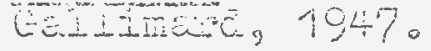

"Rélexions sur la Guillotine." Esssis. Edité par R. Quiliot et I. Taricon. Bibliotheque de la Pléiade. Panis: Gallinard et Calnann-Lévy. 1965.

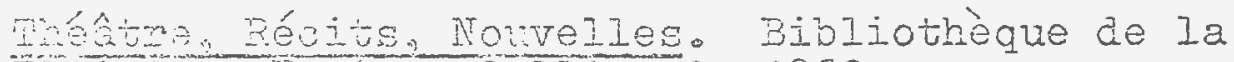
Ploiace pais: Galinara, 1962.

\section{B. OUTELES CRETRUES EN VOLUMI}

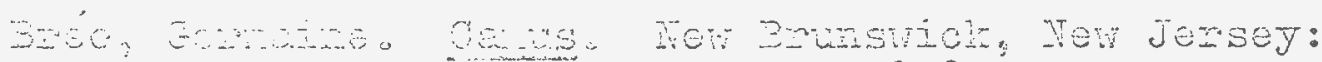

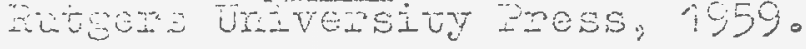

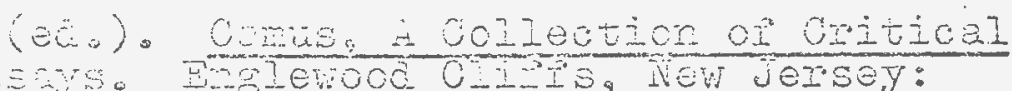

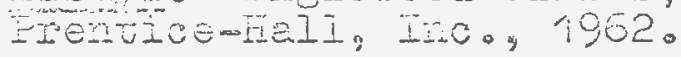

- Albert Cemaso Colmoie Jniversity Esseys ca Modem bivers, no, 1. New York: Columia University Press, 1964.

Ghanyiony: Eoberta Sur un neros payeno Ies Fssais YCIII Paris: Galimara, 195\%。

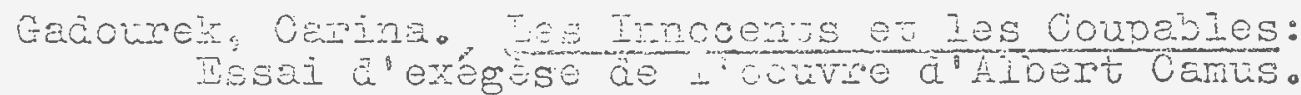
ma lagie: Houton 30, 1963.

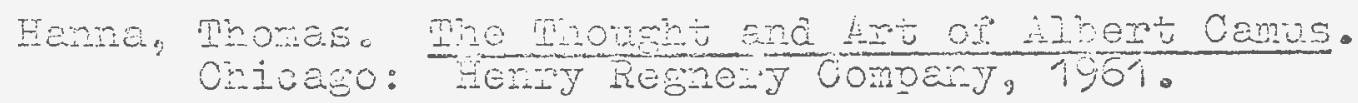




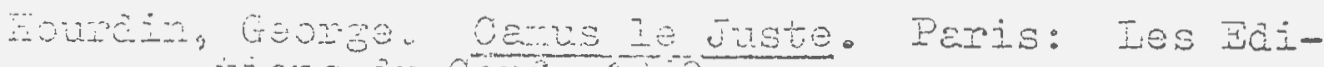
tions du Ceri; 1,000

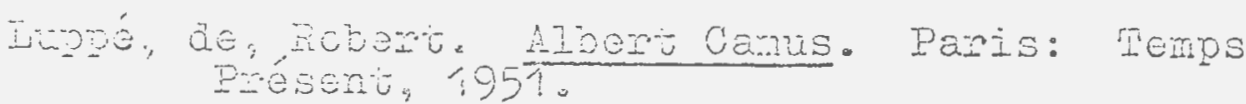

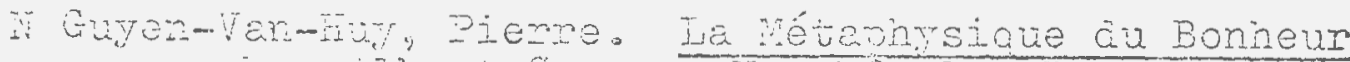

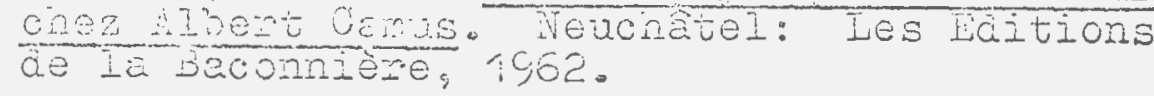

Quilit, Roger. Ia Nen et les Prisons: Essai sur

Simon, Pierre-Fenri. Présence de Camus. Bruxelles:

Thoay, Dhilip, AIBET Cinjs: A Study of his roris.

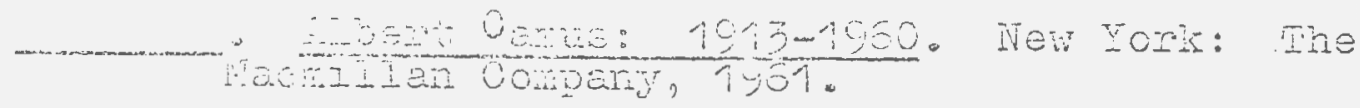

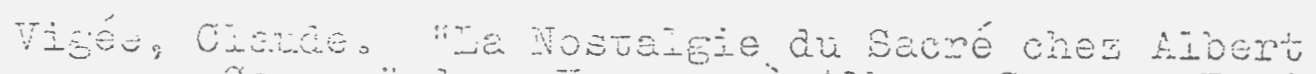

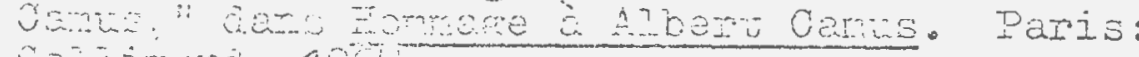
Saifinund, $190 \%$

\section{ARTICIES.}

Butpeld, Fernande. "Qamus et le Wythe du Christ."

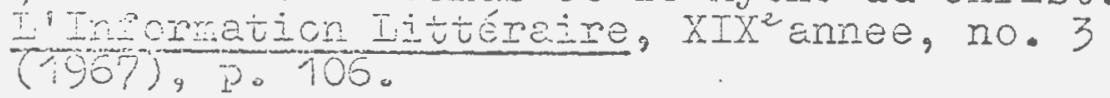

Gay-Crosien, Rayond "Les Ervers d'un échec,

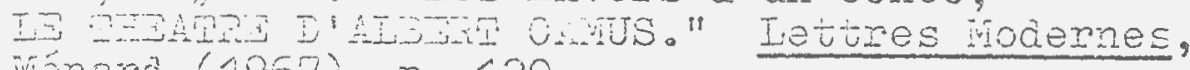
irénara $(1957)$, p. 120 。 